\title{
Cold dust and molecular gas towards the centers of Magellanic type galaxies and irregulars ${ }^{\star, \star \star}$
}

\section{The data}

\author{
M. Albrecht ${ }^{1}$, R. Chini ${ }^{1}$, E. Krügel ${ }^{2}$, S. A. H. Müller ${ }^{1}$, and R. Lemke ${ }^{1}$ \\ 1 Astronomisches Institut der Ruhr-Universität Bochum, Universitätsstr. 150, 44780 Bochum, Germany \\ e-mail: albrecht@astro.rub.de \\ 2 Max Planck Institut für Radioastronomie Bonn, Auf dem Hügel 69, 53121 Bonn, Germany
}

Received 29 July 2003 / Accepted 16 October 2003

\begin{abstract}
We present $1300 \mu \mathrm{m}$ continuum emission measurements and observations of the ${ }^{12} \mathrm{CO}(1-0)$ and $(2-1)$ transition towards the centers of 64 Magellanic type galaxies $(\mathrm{Sdm} / \mathrm{Sm})$ and irregulars ( $\mathrm{Im} / \mathrm{IO} / \mathrm{Irr})$. The sources are selected to have IRAS flux densities $S_{100 \mu \mathrm{m}} \geq 1000 \mathrm{mJy}$ and optical diameters mainly below $180^{\prime \prime}$. We were able to detect ${ }^{12} \mathrm{CO}$ towards 41 and the continuum emission towards 28 galaxies. In addition, we obtained the corresponding data for a set of 6 complementary galaxies of different morphological type.
\end{abstract}

Key words. galaxies: interstellar matter - galaxies: abundances - galaxies: Magellanic type - radio lines: galaxies radio continuum: galaxies

\section{Introduction}

Among the various constituents of the interstellar matter (ISM) the amount of dust and molecular gas are decisive quantities for our understanding of galaxy evolution, chemistry and star formation processes. As $\mathrm{H}_{2}$ lacks a permanent electric dipole moment and its emission arises only from hot or warm gas, absorption measurements against strong far-ultraviolet background sources or indirect methods are used to estimate the mass of the cold molecular component of the ISM. The most widely applied indirect methods consider the $\mathrm{CO}$ line emission or the dust mass as tracers. Dust itself is of special interest as it is strongly linked to star formation. It has the property of being very sensitive to the ultraviolet radiation of young massive stars and re-radiates it from infrared to $\mathrm{mm}$ wavelengths. A main goal of this study is to obtain measurements of the ${ }^{12} \mathrm{CO}$ line transitions and the continuum emission at $1300 \mu \mathrm{m}$ at an identical or at least similar spatial resolution. This does not only facilitate a reliable correction of the continuum emission for line contamination but - more importantly - allows a direct

Send offprint requests to: $\mathrm{M}$. Albrecht,

e-mail: albrecht@astro.rub.de

* Based on observations collected at ESO, La Silla, Chile and IRAM, Pico Veleta, Spain.

$\star \star$ The full version of Figs. 3 and 4 is only available in electronic form at http://www. edpsciences.org comparison of the two independent tracers of the amount of molecular gas.

While similar studies have been conducted for galaxies of Hubble type S0 to Sd (Chini et al. 1996; Krügel et al. 1988a, 1988b, 1990), no systematic approach to observe dust as well as molecular gas towards Magellanic type dwarfs with the same beam size has been made so far. The presented measurements will allow a comparison with galaxies of earlier Hubble type as regards their properties derived from mm observations.

In the following we describe the observational setups and the data reduction. We present the resulting flux densities of the $1300 \mu \mathrm{m}$ continuum emission. Furthermore, we show the obtained ${ }^{12} \mathrm{CO}$ spectra and list the corresponding line parameters. For a set of galaxies the ${ }^{12} \mathrm{CO}$ lines led to independent distance estimates which in conjunction with data from the literature were used to newly derive $\mathrm{HI}$ and optical properties of the objects. The data will be discussed in detail elsewhere (Albrecht et al., in prep.).

\section{Galaxy sample}

Our galaxy sample contains 31 Magellanic type spirals (Sdm, Sm), 30 Magellanic irregulars (Im) and 3 irregulars (I0, Irr) according to the classification of de Vaucouleurs et al. (1991, hereafter RC3). The objects have been taken from the compilation of morphological dwarf galaxies with known optical magnitudes, optical sizes and HI fluxes by 
Table 1. The Sdm/Sm sample.

\begin{tabular}{|c|c|c|c|c|c|c|c|c|c|c|}
\hline Name & Name & $\begin{array}{c}\text { RA } \\
(\mathrm{J} 2000.0)\end{array}$ & $\begin{array}{c}\text { Dec } \\
(\mathrm{J} 2000.0)\end{array}$ & $\begin{array}{c}{[\mathrm{Mpc}]} \\
(5) \\
\end{array}$ & $\begin{array}{c}\text { Angular } \\
\text { Size } \\
\text { [arcmin] } \\
(6)\end{array}$ & $\begin{array}{c}d_{25} \\
{[\mathrm{kpc}]} \\
(7) \\
\end{array}$ & $\begin{array}{c}S_{100 \mu \mathrm{m}} \\
(\mathrm{IRAS}) \\
{[\mathrm{mJy}]} \\
(8)\end{array}$ & $\begin{array}{c}\log M_{\mathrm{H} \mathrm{I}} \\
{\left[M_{\odot}\right]} \\
(9) \\
\end{array}$ & $\begin{array}{c}M_{\mathrm{B}} \\
{[\mathrm{mag}]} \\
(10)\end{array}$ & Morph. Type \\
\hline NGC 145 & ARP 19 & $00: 31: 45.7$ & $-05: 09: 10$ & $55.0(\mathrm{P})$ & $1.8 \times 1.3$ & 28.8 & 6156 & 9.97 & -20.9 & $\mathrm{SB}(\mathrm{s}) \mathrm{dm}$ \\
\hline NGC 178 & IC 39, & 00:39:08.5 & $-14: 10: 17$ & $19.3(\mathrm{P})$ & $2.0 \times 1.0$ & 11.2 & 2586 & 9.40 & -18.8 & $\mathrm{SB}(\mathrm{s}) \mathrm{m}$ \\
\hline NGC 959 & UGC 2002 & $02: 32: 24.0$ & $+35: 29: 42$ & $10.1(\mathrm{c})$ & $2.3 \times 1.4$ & 6.8 & 2709 & 8.49 & -17.8 & Sdm: \\
\hline IC 292 & IC 1887 & 03:10:12.9 & $+40: 45: 56$ & $39.8(\mathrm{H})$ & $1.2 \times 0.6$ & 13.9 & 4617 & 9.50 & -19.6 & $\mathrm{Sdm}$ \\
\hline DDO 36 & & 05:07:46.9 & $-16: 17: 37$ & $27.0(\mathrm{H})$ & $2.3 \times 1.4$ & 18.1 & 1528 & 9.57 & -19.0 & $\mathrm{SB}(\mathrm{s}) \mathrm{m}$ \\
\hline UGCA 103 & DDO 230 & $05: 10: 47.0$ & $-31: 35: 50$ & $12.8(\mathrm{H})$ & $3.0 \times 2.5$ & 11.2 & 1413 & 9.12 & -17.5 & $\mathrm{SB}(\mathrm{r}) \mathrm{dm}$ \\
\hline NGC 1879 & UGCA 110 & 05:19:48.2 & $-32: 08: 34$ & $16.3(\mathrm{P})$ & $2.5 \times 1.7$ & 11.9 & 1079 & 9.04 & -18.1 & $\mathrm{SB}(\mathrm{s}) \mathrm{m}$ \\
\hline UGC 4151 & & 08:04:18.7 & $+77: 49: 00$ & $30.7(\mathrm{P})$ & $1.4 \times 1.3$ & 12.5 & 2220 & 8.97 & -19.4 & Sdm: \\
\hline NGC 2537 & UGC 4274 & $08: 13: 14.7$ & $+45: 59: 26$ & 5.9 (f) & $1.7 \times 1.5$ & 2.9 & 4810 & 8.23 & -16.8 & $\mathrm{SB}(\mathrm{s}) \mathrm{m}$ pec \\
\hline NGC 2730 & UGC 4743 & 09:02:15.9 & $+16: 50: 18$ & $51.3(\mathrm{P})$ & $1.7 \times 1.3$ & 25.4 & 1996 & 9.67 & -20.3 & SBdm: \\
\hline NGC 3057 & UGC 5404 & 10:05:39.1 & $+80: 17: 08$ & $20.4(\mathrm{H})$ & $2.2 \times 1.3$ & 13.1 & 1397 & 9.06 & -18.3 & $\mathrm{SB}(\mathrm{s}) \mathrm{dm}$ \\
\hline NGC 3246 & UGC 5661 & $10: 26: 41.8$ & $+03: 51: 43$ & $28.6(\mathrm{H})$ & $2.4 \times 1.3$ & 20.0 & 1574 & 9.67 & -19.5 & SABdm \\
\hline NGC 3445 & UGC 6021 & $10: 54: 35.9$ & $+56: 59: 24$ & $27.3(\mathrm{P})$ & $1.6 \times 1.5$ & 12.7 & 2960 & 9.50 & -19.3 & $\mathrm{SAB}(\mathrm{s}) \mathrm{m}$ \\
\hline NGC 3659 & UGC 6405 & $11: 23: 45.4$ & $+17: 49: 06$ & $17.4(\mathrm{P})$ & $2.1 \times 1.1$ & 10.6 & 4073 & 9.28 & -18.7 & $\mathrm{SB}(\mathrm{s}) \mathrm{m} ?$ \\
\hline NGC 3664 & UGC 6419 & $11: 24: 25.0$ & $+03: 19: 34$ & $18.4(\mathrm{P})$ & $2.0 \times 1.9$ & 10.7 & 1962 & 9.27 & -18.4 & $\mathrm{SB}(\mathrm{s}) \mathrm{m}$ pec \\
\hline NGC 3839 & UGC 6700 & $11: 43: 54.3$ & $+10: 47: 06$ & $78.9(\mathrm{H})$ & $1.0 \times 0.5$ & 23.0 & 7169 & 10.24 & -20.4 & Sdm: \\
\hline NGC 3879 & UGC 6752 & 11:46:49.8 & $+69: 22: 59$ & $19.2(\mathrm{H})$ & $2.6 \times 0.5$ & 14.5 & 1030 & 9.24 & -18.7 & Sdm: \\
\hline NGC 3991 & UGC 6933 & $11: 57: 30.4$ & $+32: 20: 03$ & $42.8(\mathrm{P})$ & $0.6 \times 0.2$ & 7.5 & $<11150$ & 10.00 & -19.9 & $\mathrm{Sm}$ \\
\hline NGC 4234 & UGC 7309 & $12: 17: 09.2$ & $+03: 40: 59$ & $20.0(\mathrm{~V})$ & $1.3 \times 1.3$ & 7.6 & 4068 & 8.50 & -18.2 & $\left(\mathrm{R}^{\prime}\right) \mathrm{SB}(\mathrm{s}) \mathrm{m}$ \\
\hline NGC 4299 & UGC 7414 & $12: 21: 40.9$ & $+11: 30: 03$ & $20.0(\mathrm{~V})$ & $1.7 \times 1.6$ & 9.9 & $<8086$ & 9.20 & -18.8 & $\mathrm{SAB}(\mathrm{s}) \mathrm{dm}:$ \\
\hline NGC 4523 & UGC 7713 & $12: 33: 48.0$ & $+15: 10: 05$ & $20.0(\mathrm{~V})$ & $2.0 \times 1.9$ & 11.6 & 1303 & 9.26 & -17.5 & $\mathrm{SAB}(\mathrm{s}) \mathrm{m}$ \\
\hline IC 3521 & UGC 7736 & $12: 34: 39.5$ & $+07: 09: 36$ & $20.0(\mathrm{~V})$ & $1.3 \times 0.9$ & 7.6 & 2301 & 8.13 & -17.6 & SBm pec \\
\hline NGC 4625 & IC 3675 & $12: 41: 52.6$ & $+41: 16: 26$ & $8.3(\mathrm{P})$ & $2.2 \times 1.9$ & 5.3 & 3575 & 8.71 & -16.7 & $\mathrm{SAB}(\mathrm{rs}) \mathrm{m}$ pec \\
\hline NGC 5238 & UGC 8565 & $13: 34: 42.7$ & $+51: 36: 51$ & $5.2(\mathrm{~d})$ & $1.7 \times 1.4$ & 2.6 & 1213 & 7.64 & -14.8 & $\mathrm{SAB}(\mathrm{s}) \mathrm{dm}$ \\
\hline DDO 180 & & $13: 38: 10.3$ & $-09: 48: 05$ & $17.3(\mathrm{P})$ & $2.3 \times 1.9$ & 11.6 & 2075 & 9.14 & -18.6 & $\mathrm{SB}(\mathrm{s}) \mathrm{m}$ \\
\hline NGC 5433 & UGC 8954 & $14: 02: 36.0$ & $+32: 30: 38$ & $57.5(\mathrm{H})$ & $1.6 \times 0.4$ & 26.8 & 11110 & 9.79 & -20.4 & Sdm: \\
\hline NGC 5486 & UGC 9036 & $14: 07: 25.2$ & $+55: 06: 11$ & $18.2(\mathrm{P})$ & $1.9 \times 1.2$ & 10.1 & 1138 & 9.08 & -17.7 & $\mathrm{SA}(\mathrm{s}) \mathrm{m}:$ \\
\hline NGC 5630 & UGC 9270 & $14: 27: 36.7$ & $+41: 15: 27$ & $35.6(\mathrm{H})$ & $2.2 \times 0.7$ & 22.8 & 3536 & 9.68 & -19.8 & Sdm: \\
\hline NGC 6570 & UGC 11137 & 18:11:07.3 & $+14: 05: 35$ & $30.7(\mathrm{H})$ & $1.8 \times 1.1$ & 16.1 & 6250 & 9.44 & -20.1 & SB(rs)m: \\
\hline NGC $7162 A$ & & $22: 00: 35.7$ & $-43: 08: 30$ & $30.3(\mathrm{H})$ & $2.6 \times 2.3$ & 22.9 & 1122 & 9.64 & -19.1 & $\mathrm{SB}(\mathrm{s}) \mathrm{m}$ \\
\hline UGC 12082 & DDO 213 & $22: 34: 10.9$ & $+32: 51: 44$ & $10.8(\mathrm{H})$ & $2.6 \times 2.2$ & 8.2 & 1911 & 8.94 & -16.3 & $\mathrm{Sm}$ \\
\hline
\end{tabular}

Notes: (a): Clemens et al. (1999), (b): Heydari-Malayeri et al. (1990), (c): Ho et al. (1997), (d): Makarova \& Karachentsev (1998), (e): Meurer et al. (1994), (f): Sharina et al. (1999), (g): Tikhonov \& Karachentsev (1998), (h): Tully (1988), (V): Virgo cluster galaxy, distance from Federspiel et al. (1998), (H): distance from H I velocity of the RC3; (U): distance from optical velocity of the Updated Zwicky Catalogue; (P): present work.

Melisse \& Israel (1993a, 1993b). Only galaxies with IRAS flux densities at $100 \mu \mathrm{m} S_{100 \mu \mathrm{m}} \geq 1000 \mathrm{mJy}$ according to these authors were taken into account for the present study to yield a sufficient detection probability at $\mathrm{mm}$ wavelengths. Moreover, to ensure a considerable coverage of the sources with a single beam size typically of a few ten arcsec for mm observations and concerning technical limitations for the $\mathrm{ON}-\mathrm{OFF}$ separation only galaxies with a major optical axis at the 25 th mag $\operatorname{arcsec}^{-2}$ isophote $D_{25} \leq 180^{\prime \prime}$ were selected. Six galaxies are added to the sample which do not fulfil the size criterion (NGC 1569, NGC 2366, NGC 2976, NGC 3077,
NGC 3396 and UGCA 105). Except NGC 3396 these galaxies were chosen because of their high IRAS flux densities at $100 \mu \mathrm{m}$ and low absolute blue magnitudes which make them especially interesting for a study of morphological dwarf galaxies. NGC 3396 has been taken into account as its major optical axis exceeds the size limit by only $0.1^{\prime}$. Melisse \& Israel (1993a, 1993b) explicitly exclude peculiar galaxies according to the morphological classification of de Vaucouleurs et al. (1976, hereafter RC2). Nevertheless, following the classification of the RC3 our sample contains 16 peculiar galaxies. We additionally obtained measurements of the ${ }^{12} \mathrm{CO}$ line and/or 
Table 2. The Im/I0/Irr sample.

\begin{tabular}{|c|c|c|c|c|c|c|c|c|c|c|}
\hline Name & Name & $\begin{array}{c}\text { RA } \\
(\mathrm{J} 2000.0)\end{array}$ & $\begin{array}{c}\text { Dec } \\
(\mathbf{J} 2000.0)\end{array}$ & $\begin{array}{c}{[\mathrm{Mpc}]} \\
(5)\end{array}$ & $\begin{array}{c}\text { Angular } \\
\text { Size } \\
\text { [arcmin] } \\
(6)\end{array}$ & $\begin{array}{c}{[\mathrm{kpc}]} \\
(7)\end{array}$ & $\begin{array}{c}S_{100 \mu \mathrm{m}} \\
(\mathrm{IRAS}) \\
{[\mathrm{mJy}]} \\
(8)\end{array}$ & $\begin{array}{c}{\left[M_{\odot}\right]} \\
(9)\end{array}$ & $\begin{array}{c}\text { [mag] } \\
(10)\end{array}$ & Morph. Type \\
\hline ARP 004 & DDO 14 & $01: 48: 25.7$ & $-12: 22: 55$ & $21.5(\mathrm{H})$ & $2.8 \times 2.3$ & 17.5 & 1601 & 9.35 & -18.0 & $\mathrm{IAB}(\mathrm{rs}) \mathrm{m}$ \\
\hline NGC 899 & UGCA 26 & $02: 21: 53.1$ & $-20: 49: 23$ & $20.7(\mathrm{H})$ & $1.9 \times 1.3$ & 11.4 & 3678 & 9.86 & -18.6 & $\mathrm{IB}(\mathrm{s}) \mathrm{m}$ \\
\hline NGC 1140 & Mrk 1063 & $02: 54: 33.6$ & $-10: 01: 40$ & $19.6(\mathrm{P})$ & $1.7 \times 0.9$ & 9.7 & 3184 & 9.63 & -18.9 & IBm pec: \\
\hline NGC 1602 & & $04: 27: 53.7$ & $-55: 03: 26$ & $20.7(\mathrm{H})$ & $1.9 \times 1.1$ & 11.4 & 1567 & 9.11 & -18.2 & $\mathrm{IB}(\mathrm{s}) \mathrm{m}$ pec: \\
\hline NGC 1569 & UGC 3056 & $04: 30: 49.0$ & $+64: 50: 53$ & $2.2(\mathrm{~h})$ & $3.6 \times 1.8$ & 2.3 & 31748 & 8.11 & -17.3 & $\mathrm{IBm}$ \\
\hline UGC 3234 & DDO 35 & $05: 03: 24.6$ & $+16: 24: 16$ & $18.7(\mathrm{H})$ & $1.8 \times 1.8$ & 9.8 & 2505 & 9.31 & -18.0 & Im: \\
\hline UGCA 105 & & $05: 14: 15.0$ & $+62: 34: 31$ & $4.0(\mathrm{~h})$ & $5.5 \times 3.5$ & 6.4 & 4710 & 8.91 & -15.7 & $\operatorname{Im} ?$ \\
\hline NGC 2366 & UGC 3851 & $07: 28: 54.6$ & $+69: 12: 57$ & $2.9(\mathrm{~h})$ & $8.1 \times 3.3$ & 6.8 & 4578 & 8.84 & -16.4 & $\mathrm{IB}(\mathrm{s}) \mathrm{m}$ \\
\hline NGC 2415 & UGC 3930 & $07: 36: 56.4$ & $+35: 14: 31$ & $50.4(\mathrm{H})$ & $0.9 \times 0.9$ & 13.2 & 12890 & 9.75 & -20.9 & $\operatorname{Im} ?$ \\
\hline NGC 2719 & UGC 4718 & 09:00:15.4 & $+35: 43: 40$ & $42.0(\mathrm{H})$ & $1.3 \times 0.3$ & 15.9 & 2641 & 10.00 & -20.1 & Im pec? \\
\hline NGC 2915 & & 09:26:11.5 & $-76: 37: 36$ & $5.3(\mathrm{e})$ & $1.9 \times 1.0$ & 2.9 & 2120 & 8.82 & -16.3 & I0 \\
\hline NGC 3026 & UGC 5279 & 09:50:55.4 & $+28: 33: 05$ & $19.8(\mathrm{H})$ & $2.7 \times 0.8$ & 15.6 & 1339 & 9.12 & -18.4 & $\mathrm{Im}$ \\
\hline NGC 3077 & UGC 5398 & 10:03:20.6 & $+68: 44: 04$ & $2.1(\mathrm{~h})$ & $5.4 \times 4.5$ & 3.3 & 26430 & 8.57 & -16.2 & I0 pec \\
\hline UGC 5720 & Mrk 33 & $10: 32: 31.9$ & $+54: 24: 03$ & $19.1(\mathrm{H})$ & $1.0 \times 0.9$ & 5.6 & 5317 & 8.63 & -18.0 & Im pec \\
\hline NGC 3396 & UGC 5935 & $10: 49: 55.2$ & $+32: 59: 27$ & $22.4(\mathrm{P})$ & $3.1 \times 1.2$ & 20.2 & 16800 & 9.69 & -19.4 & IBm pec \\
\hline UGC 6345 & DDO 94 & 11:20:15.6 & $+02: 31: 31$ & $21.3(\mathrm{H})$ & $2.3 \times 1.3$ & 14.3 & 1851 & 9.47 & -18.3 & $\mathrm{IB}(\mathrm{s}) \mathrm{m}$ \\
\hline NGC 3738 & UGC 6565 & $11: 35: 48.8$ & $+54: 31: 26$ & $4.3(\mathrm{~h})$ & $2.5 \times 1.9$ & 3.1 & 2405 & 8.15 & -16.2 & Irr \\
\hline NGC 4032 & UGC 6995 & $12: 00: 32.9$ & $+20: 04: 26$ & $20.0(\mathrm{~V})$ & $1.9 \times 1.8$ & 11.1 & 1547 & 9.25 & -18.9 & Im: \\
\hline NGC 4190 & UGC 7232 & $12: 13: 44.7$ & $+36: 38: 03$ & $3.5(\mathrm{~g})$ & $1.7 \times 1.5$ & 1.7 & 1262 & 7.78 & -14.4 & Im pec \\
\hline NGC 4194 & UGC 7241 & $12: 14: 09.7$ & $+54: 31: 38$ & $33.5(\mathrm{H})$ & $1.8 \times 1.1$ & 17.5 & 25880 & 9.28 & -19.8 & IBm pec \\
\hline NGC 4485 & UGC 7648 & $12: 30: 31.1$ & $+41: 42: 01$ & $8.0(\mathrm{H})$ & $2.3 \times 1.6$ & 5.4 & $<3730$ & 8.68 & -17.3 & $\mathrm{IB}(\mathrm{s}) \mathrm{m}$ pec \\
\hline UGC 7690 & & $12: 32: 26.8$ & $+42: 42: 18$ & $7.3(\mathrm{H})$ & $1.7 \times 1.6$ & 3.6 & 1209 & 8.42 & -15.9 & $\mathrm{Im}:$ \\
\hline IC 3476 & UGC 7695 & $12: 32: 41.9$ & $+14: 03: 00$ & $20.0(\mathrm{~V})$ & $2.1 \times 1.8$ & 12.2 & 2384 & 8.66 & -18.7 & $\mathrm{IB}(\mathrm{s}) \mathrm{m}:$ \\
\hline NGC 4532 & UGC 7726 & $12: 34: 19.3$ & $+06: 28: 07$ & $20.0(\mathrm{~V})$ & $2.9 \times 1.1$ & 16.9 & 16210 & 9.75 & -19.6 & $\mathrm{IBm}$ \\
\hline NGC 4630 & UGC 7871 & $12: 42: 31.2$ & $+03: 57: 32$ & $20.0(\mathrm{~V})$ & $1.8 \times 1.3$ & 10.5 & 4189 & 8.88 & -18.5 & $\mathrm{IB}(\mathrm{s}) \mathrm{m} ?$ \\
\hline NGC 4810 & UGC 8034 & $12: 54: 51.2$ & $+02: 38: 25$ & $12.1(\mathrm{U})$ & $1.9 \times 0.8$ & 6.7 & 1213 & - & -16.1 & Im pec \\
\hline UGC 8303 & DDO 166 & $13: 13: 17.6$ & $+36: 13: 03$ & $12.7(\mathrm{H})$ & $2.2 \times 1.9$ & 8.1 & 1420 & 8.75 & -17.0 & $\mathrm{IAB}(\mathrm{s}) \mathrm{m}$ \\
\hline NGC 5408 & & $14: 03: 21.0$ & $-41: 22: 44$ & $4.9(\mathrm{~h})$ & $1.6 \times 0.8$ & 2.3 & 2157 & 8.63 & -16.8 & $\mathrm{IB}(\mathrm{s}) \mathrm{m}$ \\
\hline NGC 5464 & & 14:07:04.4 & $-30: 01: 01$ & $35.9(\mathrm{H})$ & $1.3 \times 0.8$ & 13.6 & 2964 & 9.81 & -19.9 & $\mathrm{IB}(\mathrm{s}) \mathrm{m} ?$ \\
\hline ARP 261 & DDO 197 & $14: 49: 30.6$ & $-10: 10: 24$ & $24.6(\mathrm{H})$ & $3.0 \times 2.0$ & 21.5 & 2799 & 9.65 & -19.1 & $\mathrm{IB}(\mathrm{s}) \mathrm{m}$ pec \\
\hline NGC 5798 & UGC 9628 & $14: 57: 37.9$ & $+29: 58: 06$ & $24.1(\mathrm{P})$ & $1.4 \times 1.0$ & 9.8 & 2260 & 8.99 & -18.5 & Im: \\
\hline IC 4662 & & $17: 47: 06.4$ & $-64: 38: 25$ & $2.0(\mathrm{~b})$ & $2.8 \times 1.6$ & 1.6 & 11230 & 8.13 & -15.2 & $\mathrm{IBm}$ \\
\hline NGC 7292 & UGC 12048 & $22: 28: 25.8$ & $+30: 17: 33$ & $13.5(\mathrm{P})$ & $2.1 \times 1.7$ & 8.2 & 2725 & 8.96 & -18.0 & $\mathrm{IBm}$ \\
\hline
\end{tabular}

Notes: See Table 1.

Table 3. The complementary sample.

\begin{tabular}{|c|c|c|c|c|c|c|c|c|c|c|}
\hline Name & Name & $\begin{array}{c}\text { RA } \\
(\mathrm{J} 2000.0)\end{array}$ & $\begin{array}{c}\text { Dec } \\
(\mathrm{J} 2000.0) \\
(4)\end{array}$ & $\begin{array}{c}D \\
{[\mathrm{Mpc}]} \\
(5)\end{array}$ & $\begin{array}{l}\text { Angular } \\
\text { Size } \\
\text { [arcmin] } \\
(6)\end{array}$ & $\begin{array}{c}d_{25} \\
{[\mathrm{kpc}]} \\
(7)\end{array}$ & $\begin{array}{c}S_{100 \mu \mathrm{m}} \\
(\text { IRAS) } \\
{[\mathrm{mJy}]} \\
(8)\end{array}$ & $\begin{array}{c}\log M_{\mathrm{HI}} \\
{\left[M_{\odot}\right]} \\
(9)\end{array}$ & $\begin{array}{c}M_{\mathrm{B}} \\
{[\mathrm{mag}]} \\
(10)\end{array}$ & Morph. Type \\
\hline NGC 1012 & UGC 2141 & $02: 39: 14.9$ & $+30: 09: 06$ & $12.9(\mathrm{P})$ & $2.5 \times 1.1$ & 9.4 & 8464 & 9.36 & -18.3 & S0/a? \\
\hline UGCA 116 & IIZw40 & $05: 55: 42.6$ & $+03: 23: 30$ & $10.0(\mathrm{P})$ & $0.6 \times 0.2$ & 1.7 & $<19720$ & 8.70 & -17.1 & $\mathrm{Sbc}$ \\
\hline NGC 2976 & UGC 5221 & $09: 47: 15.3$ & $+67: 55: 00$ & $2.1(\mathrm{~h})$ & $5.9 \times 2.7$ & 3.6 & 29710 & 7.82 & -16.3 & SAc pec \\
\hline UGCA 247 & DDO 239 & $11: 48: 45.8$ & $-28: 17: 41$ & $25.6(\mathrm{P})$ & $2.5 \times 2.2$ & 18.6 & 3131 & 9.63 & -19.5 & $\mathrm{SB}(\mathrm{s}) \mathrm{d}:$ \\
\hline NGC 7107 & & $21: 42: 26.5$ & $-44: 47: 25$ & $29.3(\mathrm{H})$ & $2.0 \times 1.5$ & 17.0 & 1534 & 9.38 & -19.3 & $\mathrm{SB}(\mathrm{rs}) \mathrm{cd}$ \\
\hline NGC 7732 & UGC 12738 & $23: 41: 34.0$ & $+03: 43: 29$ & $39.0(\mathrm{P})$ & $1.9 \times 0.6$ & 21.6 & 2231 & 10.03 & -19.6 & Scd pec sp \\
\hline
\end{tabular}

Notes: See Table 1. 
continuum emission towards 6 complementary galaxies of different morphological type. In the following we have divided the complete set of observed galaxies into three sub-samples: Magellanic type spirals ( $\mathrm{Sdm} / \mathrm{Sm})$, irregulars and Magellanic type irregulars (Im/I0/Irr) and the sample of complementary sources. The name, alternative name and coordinates of the galaxies are given in Tables 1-3 for the corresponding subsamples. To estimate the distances to the sources the heliocentric radial velocities based on H I observations have been extracted from the NASA/IPAC Extragalactic Database (NED) ${ }^{1}$ and have been converted to velocities with respect to the local standard of rest $v_{\mathrm{lsr}}$. The radial velocity of NGC 4810 is based on optical observations from the RC3. In case of a ${ }^{12} \mathrm{CO}$ detection with a single Gauss component the central velocity of the ${ }^{12} \mathrm{CO}$ line (see Sect. 4.1) is used instead. For galaxies with $v_{\text {lsr }}>600 \mathrm{~km} \mathrm{~s}^{-1}$ the distances have been derived using a Hubble constant of $H_{0}=75 \mathrm{~km} \mathrm{~s}^{-1} \mathrm{Mpc}^{-1}$. The distances to galaxies with $v_{\mathrm{lsr}} \leq 600 \mathrm{~km} \mathrm{~s}^{-1}$ have been taken from the literature as identified in the notes to Table 1. Eight galaxies of the sample are members of the Virgo cluster, for which a mean distance of 20.0 Mpc is assumed (Federspiel et al. 1998) without applying Virgo-centric infall corrections. Column (5) of Tables 1-3 lists the adopted distances.

\section{Observations and data reduction}

The observations of the ${ }^{12} \mathrm{CO}(1-0)$ and (2-1) line transitions and the $1300 \mu \mathrm{m}$ continuum emission were obtained at the IRAM $30 \mathrm{~m}$ telescope (MRT) and the $15 \mathrm{~m}$ Swedish ESO Submillimeter Telescope (SEST) between 1997 and 2002. The telescopes provide beam sizes (HPBW) of 45" (SEST) and 24" (MRT) at $115 \mathrm{GHz}$ and 24" (SEST) and 11" (MRT) at $230 \mathrm{GHz}$.

\section{1. ${ }^{12}$ CO line emission}

At the SEST a balanced ON-OFF dual beam switching mode was applied with a separation between the ON and OFF beams of $11^{\prime} 50^{\prime \prime}$ in azimuth at a frequency of $6 \mathrm{~Hz}$. The dual channel $115 / 230 \mathrm{GHz}$ SIS receiver was tuned to the central H I velocity in each source. Spectra were obtained with two acousto optical spectrometers (LR1 and LR2) providing 1440 channels each and a width of $0.7 \mathrm{MHz}$ per channel. The total bandwidth available was $1 \mathrm{GHz}$ at both backends, yielding a velocity resolution of $1.8 \mathrm{~km} \mathrm{~s}^{-1}$ and $0.9 \mathrm{~km} \mathrm{~s}^{-1}$ for ${ }^{12} \mathrm{CO}(1-0)$ and $(2-1)$, respectively. Pointing and focus were checked before each integration about every two hours on bright $\mathrm{SiO}$ masers and planets. The pointing accuracy was found to be always better than $5^{\prime \prime}$ in azimuth and elevation. Regular calibrations were performed using the standard chopper wheel method (Ulich \& Haas 1976). System temperatures usually varied between $300 \mathrm{~K}$ and $500 \mathrm{~K}$, infrequently rising higher due to bad weather conditions.

1 This research has made use of the NASA/IPAC Extragalactic Database (NED) which is operated by the Jet Propulsion Laboratory, California Institute of Technology, under contract with the National Aeronautics and Space Administration.
Table 4. Velocity resolution for those cases differing from $10 \mathrm{~km} \mathrm{~s}^{-1}$.

\begin{tabular}{llcc}
\hline \hline Name & Telescope & ${ }^{12}$ CO transition & $\begin{array}{c}\delta v \\
{\left[\mathrm{~km} \mathrm{~s}^{-1}\right]}\end{array}$ \\
\hline NGC 2730 & MRT & $2-1$ & 12 \\
& SEST & $1-0$ & 15 \\
NGC 3664 & MRT & $1-0$ & 13 \\
& MRT & $2-1$ & 12 \\
NGC 5486 & MRT & $2-1$ & 13 \\
NGC 7732 & MRT & $1-0$ & 21 \\
& SEST & $1-0$ & 15 \\
\hline
\end{tabular}

At the MRT a wobbler switching mode was performed at a frequency of $0.5 \mathrm{~Hz}$ with a beam throw between $150^{\prime \prime}$ and $240^{\prime \prime}$ in azimuth depending on the size of the source. Two $3 \mathrm{~mm}$ SIS receivers (A100, B100) and two $1.3 \mathrm{~mm}$ SIS receivers (A230, B230) were used to observe both polarisations of the ${ }^{12} \mathrm{CO}(1-0)$ and $(2-1)$ transitions simultaneously. The $3 \mathrm{~mm}$ SIS receivers were connected to a low resolution filter-bank with a total bandwidth of $1 \mathrm{GHz}$ and a resolution of $1 \mathrm{MHz}$. The filter-bank was split into two parts with 512 channels for each receiver. As backend for the $1.3 \mathrm{~mm}$ SIS receivers an auto-correlator was used providing a bandwidth of $512 \mathrm{MHz}$ and 409 channels with a resolution of $1.25 \mathrm{MHz}$ for each receiver. This yields a velocity resolution of $2.6 \mathrm{~km} \mathrm{~s}^{-1}$ and $1.6 \mathrm{~km} \mathrm{~s}^{-1}$ for ${ }^{12} \mathrm{CO}(1-0)$ and (2-1), respectively. Pointing and focus were checked before each integration about every two hours on continuum sources and planets. The pointing accuracy was found to be always better than $4^{\prime \prime}$ in azimuth and elevation. Calibrations were performed frequently using the chopper wheel method. System temperatures usually varied between $200 \mathrm{~K}$ and $400 \mathrm{~K}$, again infrequently rising higher due to bad weather conditions.

All obtained spectra were reduced using the CLASS software package $^{2}$ (Buisson et al. 1997). Multiple scans were averaged weighted by a factor of $t / T_{\text {sys }}^{2}$, where $t$ is the integration time and $T_{\text {sys }}$ the system temperature of the individual scans. Scans showing nonlinear baselines or artificial features were rejected. The intensity scale of the resulting spectra in corrected antenna temperature $T_{\mathrm{A}}^{*}$ was converted to main beam brightness temperature $T_{\mathrm{mb}}$. From the averaged spectra linear baselines were subtracted. All spectra were boxcar-smoothed to a resolution of $\delta v=10 \mathrm{~km} \mathrm{~s}^{-1}$. In a few cases spectra were smoothed to lower resolutions to receive a better signal-tonoise ratio as given in Table 4. For all spectra where a molecular line was detected, a Gauss function was fitted to determine the central velocity and velocity width and to check the signalto-noise ratio $S / N$. Spectra clearly showing more than one velocity component were fitted using up to three Gaussians.

In case of $S / N \geq 3$, the velocity integrated ${ }^{12} \mathrm{CO}$ line intensity $I=\int T_{\mathrm{mb}} \mathrm{d} v$ was determined by numerical integration of the smoothed spectra within the limits set by the line. The errors were calculated according to Elfhag et al. (1996): Assuming a perfect baseline, the line uncertainty is given by

$\Delta I_{1}=\sigma \sqrt{n} \delta v$,

2 The CLASS package is part of the GILDAS software. The manual can be retrieved via the IRAM web-page. 
where $\sigma$ is the rms noise per channel, $n$ the number of channels covered by the line and $\delta v$ the velocity resolution per channel. For linear baselines the baseline fitting uncertainty can be determined as

$\Delta I_{\mathrm{b}}=\sigma n \delta v \sqrt{\frac{1}{N-n}}$,

where $N$ is the total number of channels in the spectra. This results in a total error of the integrated ${ }^{12} \mathrm{CO}$ line intensities given by

$\Delta I=\sqrt{\Delta I_{1}^{2}+\Delta I_{\mathrm{b}}^{2}}=\sigma \delta v \sqrt{n+\frac{n^{2}}{N-n}}$.

Assuming uncorrelated channel-to-channel fluctions we have calculated upper limits in case of non-detections $(S / N<3)$ as

$I<3 \sigma \sqrt{\Delta v_{\mathrm{tot}}\left({ }^{12} \mathrm{CO}\right) \delta v}$,

where $\Delta v_{\text {tot }}\left({ }^{12} \mathrm{CO}\right)$ is the expected total velocity width of the ${ }^{12} \mathrm{CO}$ line, which is not actually obtained. To derive secure upper limits for $I$ we use the full velocity width of the H I line at $20 \%$ or $50 \%$ maximum power multiplied by 1.69 or 2.58 , respectively, as an upper limit for $\Delta v_{\text {tot }}\left({ }^{12} \mathrm{CO}\right) . \Delta v_{20}(\mathrm{H} \mathrm{I})$ and $\Delta v_{50}(\mathrm{H} \mathrm{I})$ are taken from the RC3. In case of a Gaussian shape of the HI spectrum this would result in the full $\mathrm{HI}$ velocity width at $1 \%$ of the maximum power: $\Delta v_{1}(\mathrm{H} \mathrm{I})=1.69 \Delta v_{20}(\mathrm{H} \mathrm{I})$ or $\Delta v_{1}(\mathrm{HI})=2.58 \Delta v_{50}(\mathrm{HI})$. To inspect the reliability of this approach we have compared the resulting values for $\Delta v_{1}(\mathrm{HI})$ with the total velocity width $\Delta v_{\text {tot }}\left({ }^{12} \mathrm{CO}\right)$ for those cases where a clear detection $(S / N \geq 3)$ was obtained. Figure 1 shows the ratio of $\Delta v_{\text {tot }}\left({ }^{12} \mathrm{CO}\right)$ to $\Delta v_{1}(\mathrm{HI})$ as a function of projected beam size, where $\Delta v_{\text {tot }}\left({ }^{12} \mathrm{CO}\right)$ is determined from the smoothed spectra. All ${ }^{12} \mathrm{CO}$ detections, i.e. both transitions and both telescopes, irrespective of the number of fitted Gaussians are displayed. Except for the extreme case of NGC 4194 all galaxies posess values for the ratio $\Delta v_{\text {tot }}\left({ }^{12} \mathrm{CO}\right) / \Delta v_{1}(\mathrm{H}$ I) below one showing that $\Delta v_{1}(\mathrm{HI})$ can be used as a secure approximation for $\Delta v_{\text {tot }}\left({ }^{12} \mathrm{CO}\right)$ in case of non-detections.

Figure 1 shows the tendency of increasing ${ }^{12} \mathrm{CO}$ line width normalised on the $\mathrm{H}$ I width with increasing coverage of the source by a single beam. This can be expected as the ${ }^{12} \mathrm{CO}$ beam resolves a galaxy while the H I width refers to the entire object. Evidently, beam projection effects play a key role in analysing the data presented here and will be a major topic in the subsequent discussion (see Paper II). Especially the question arises, what fraction of the total flux is detected.

\section{2. $1300 \mu m$ continuum emission}

Observations of the $1300 \mu \mathrm{m}$ continuum emission at the MRT were carried out using the MPIfR 37-channel bolometer array (Kreysa 1990; Thum et al. 1992). Each channel of the array has a half power beam width of $11^{\prime \prime}$. The channels are arranged in a hexagonal structure with a pixel-to-pixel separation of $23^{\prime \prime}$. A filter set coupled to the atmospheric window provides a bandwidth of $50 \mathrm{GHz}$ around a central wavelength of $1250 \mu \mathrm{m}$. All observations were made in a symmetrical ON-OFF mode with a beam separation between $70^{\prime \prime}$ and $120^{\prime \prime}$ in azimuth and a

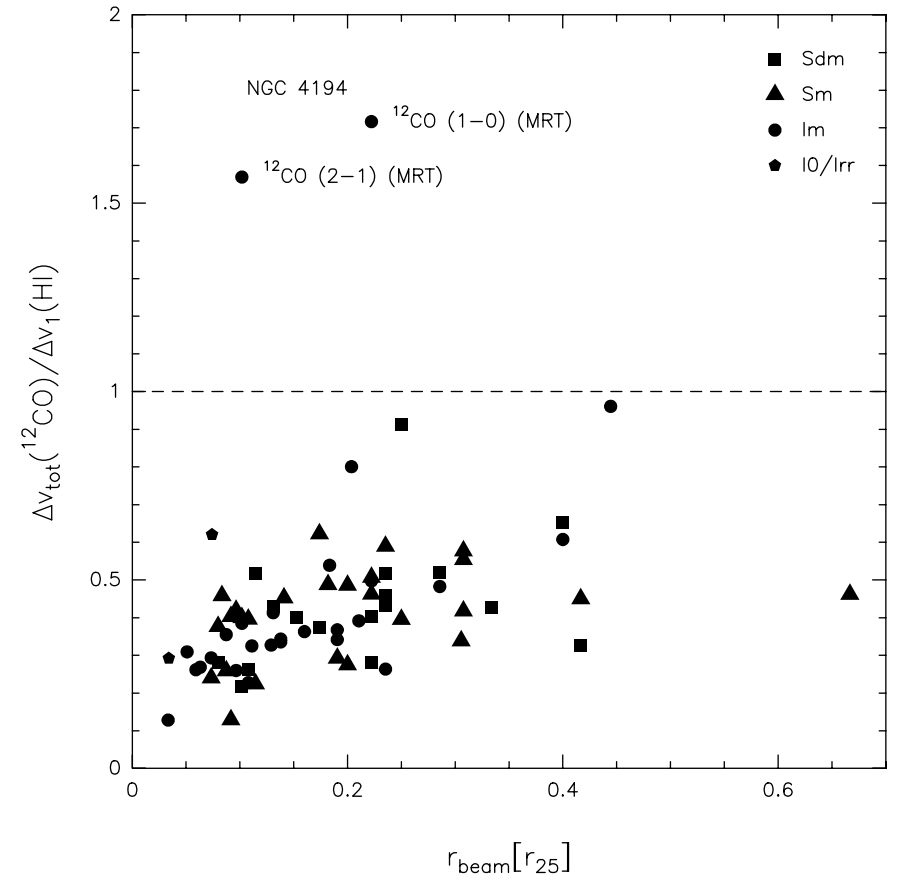

Fig. 1. Ratio of the total ${ }^{12} \mathrm{CO}$ velocity width to the $\mathrm{H}$ I velocity width at $1 \%$ of the maximum power versus the projected beam size in units of the optical radius. All ${ }^{12} \mathrm{CO}$ detections (i.e. both transitions and both telescopes) are displayed. The dashed line denotes equality.

wobbling frequency of $0.51 \mathrm{~Hz}$. Integration times varied between 30 min and 2 hours per source. Due to the Nasmythsystem the bolometer array rotates with respect to the source as a function of hour angle and elevation. To ensure that the channel positions with respect to the galaxy do not move, the integrations were conducted during those time intervals when the rotation of the array had its minimum. Pointing and focus were checked before each integration about every two hours on strong continuum sources and planets. The pointing accuracy was found to be mostly better than $4^{\prime \prime}$ in azimuth and elevation. To obtain the atmospheric opacity the sky emission was measured regularly at a number of elevation angles.

At the SEST the continuum observations were carried out using a single channel bolometer of the MPIfR. The characteristics of this bolometer are similar to the individual elements of the array used at the MRT. It provides a bandwidth of about $50 \mathrm{GHz}$ centered at a wavelength of $1270 \mu \mathrm{m}$. A dual beam switching mode (ON-OFF) with a separation of $120^{\prime \prime}$ between the ON- and OFF-beam was applied for all observations. Again pointing and focus were checked before each integration about every two hours on strong continuum sources and planets and the atmospheric opacity was determined regularly. The pointing accuracies are similar to those at the MRT.

The reduction of single-channel data is straightforward and consists mainly of baseline subtraction and weighted averaging. On the other hand the use of multiple channels provides the opportunity of correlated sky-noise suppression and the subtraction of mean background emission. We have developed a 
reduction software package in the framework of NIC ${ }^{3}$ providing a sophisticated sky-noise suppression and the selection of arbitrary channels for the background determination. As a result signal-to-noise ratios increased by about $10-15 \%$ in comparison to the values provided by common software could be achieved for most observations.

\section{Results}

\section{1. ${ }^{12} \mathrm{CO}$ line emission}

Of a total of 67 galaxies observed ${ }^{12} \mathrm{CO}$ was detected in 41 sources $(\mathrm{Sdm} / \mathrm{Sm}: 21, \mathrm{Im} / \mathrm{I} 0 / \mathrm{Irr}: 15$, complementary sample: 5) yielding detection rates of $72 \%$ and $47 \%$ for the $\mathrm{Sdm} / \mathrm{Sm}$ and Im/I0/Irr subsample, respectively. Figure 3 shows the spectra taken at the MRT and Fig. 4 those taken at the SEST at a resolution of $10 \mathrm{~km} \mathrm{~s}^{-1}$ (for exceptions see Table 4). The results are presented in Table 5, where Col. (1) gives the object name and Col. (2) identifies the ${ }^{12} \mathrm{CO}$ transition. The parameters of the Gaussian fits are listed in Cols. (3)-(5) for the MRT and Cols. (8)-(10) for the SEST observations, where Cols. (3) and (8) give the central velocities with respect to the local standard of rest, Cols. (4) and (9) the line width (FWHM) and Cols. (5) and (10) the peak values of the main beam brightness temperature. In case the spectrum is fit by more than one Gaussian, the parameters of all components are listed. The rms noise per channel is contained in Cols. (6) and (11) and the velocity integrated line intensity including the total error or the corresponding upper limit is given in Cols. (7) and (12). All values correspond to a velocity resolution of $10 \mathrm{~km} \mathrm{~s}^{-1}$ except for those cases stated in Table 4.

\section{2. $1300 \mu m$ continuum emission}

Of a total of 52 galaxies observed the continuum emission at $1300 \mu \mathrm{m}$ has been detected towards 28 sources $(\mathrm{Sdm} / \mathrm{Sm}$ : 9, Im/I0/Irr: 16, complementary sample: 3 ) resulting in detection rates of $47 \%$ and $57 \%$ for the $\mathrm{Sdm} / \mathrm{Sm}$ and $\mathrm{Im} / \mathrm{I} 0 / \mathrm{Irr}$ subsample, respectively. In Table 6 the results are listed, where Col. (1) identifies the name, Cols. (2)-(7) refer to MRT and Cols. (8)-(10) to SEST observations. The flux density from the central channel of the multi-channel array at the MRT is given in Col. (2), where for signal-to-noise ratios $S / N<3$ upper limits are given quantified as three times the rms noise. The corresponding errors refer to the signal noise solely and do not include the calibration uncertainty which was determined to be $16 \%$. In case signal-to-noise ratios $S / N \geq 3$ were reached for channels apart from the central one we have summed up the corresponding flux densities including the center position. The values are given in Col. (3) and Col. (4) lists the total number of the mentioned channels. In Col. (8) the flux density resulting from the single-channel bolometer at the SEST is given, where the calibration uncertainty of $21 \%$ again is not included in the total error.

The thermal continuum emission observed at $1300 \mu \mathrm{m}$ is affected by contamination from molecular lines. The strongest

\footnotetext{
3 The NIC package is part of the GILDAS software. The manual can be retrieved via the IRAM web-page.
}

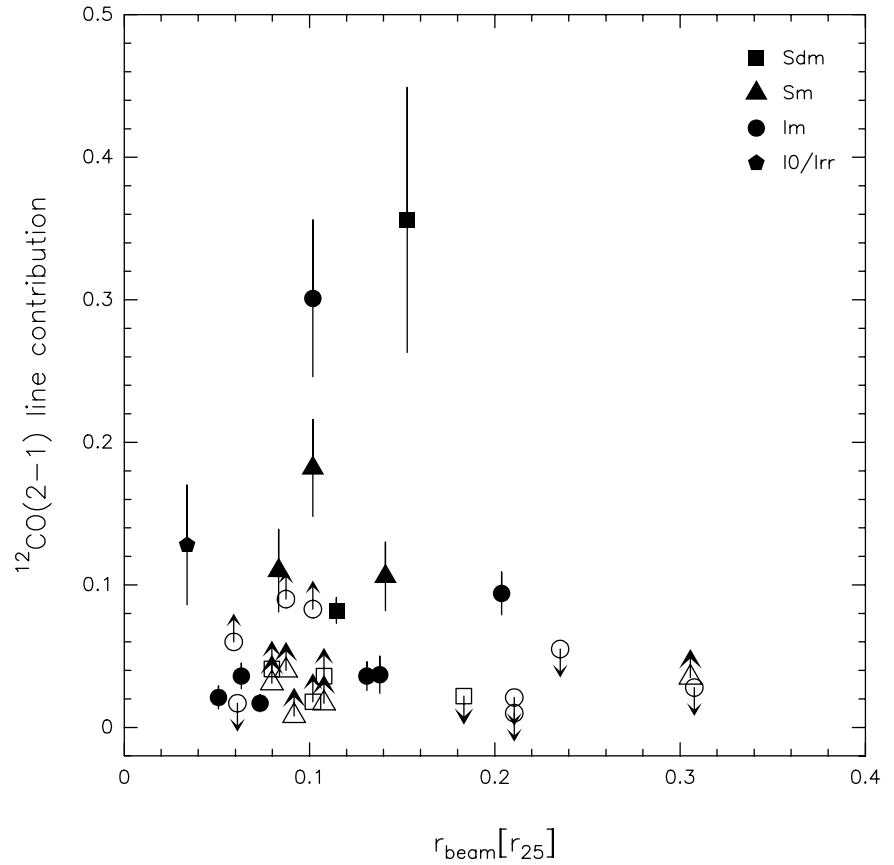

Fig. 2. Fractional ${ }^{12} \mathrm{CO}(2-1)$ line contribution to the $1300 \mu \mathrm{m}$ continuum emission versus the projected beam size in units of the optical radius. Vertical bars mark the rms of the individual values. Open symbols denote upper or lower limits.

lines emitted within the bolometer bandwidth are ${ }^{12} \mathrm{CO}(2-1)$, ${ }^{13} \mathrm{CO}(2-1), \mathrm{C}^{18} \mathrm{O}(2-1)$ and $\mathrm{CS}(5-4)$. According to Braine et al. (1995) the line contribution is given by

$S_{\text {line }}=\frac{2 k}{\lambda^{3} \Delta f} \frac{2 \pi \theta^{2}}{8 \ln 2} I$

where $k$ is the Boltzmann constant, $\lambda$ the wavelength, $\Delta f$ the bandwidth, $\theta$ the half power beam width (HPBW) of the bolometer and $I$ the velocity integrated line intensity. For a bandwidth of $\Delta f=50 \mathrm{GHz}$ and a beam size of $\theta=11^{\prime \prime}$ at the MRT and $\theta=24^{\prime \prime}$ at the SEST this leads to a contribution of the ${ }^{12} \mathrm{CO}(2-1)$ line of $S_{{ }^{12} \mathrm{CO}(2-1)}=0.081 I_{\mathrm{CO}(2-1)}$ at the MRT and $S_{{ }^{12} \mathrm{CO}(2-1)}=0.386 I_{\mathrm{CO}(2-1)}$ at the SEST, where $S_{{ }^{12} \mathrm{CO}(2-1)}$ is given in mJy and $I^{12} \mathrm{CO}(2-1)$ in $\mathrm{K} \mathrm{km} \mathrm{s}^{-1}$. We were able to determine the line contribution for 14 galaxies with a mean of $11 \pm 10 \%$. The values are listed in Cols. (3) and (9). In case no exact value could be derived we used the mean contribution to correct for line contamination except for those cases where the upper limits are not in accordance with the mean (MRT: NGC 3839, ARP 261; SEST: NGC 899, NGC 1140, NGC 1602, NGC 5464). In these cases we used the individual upper limits as a more reliable approximation for the correction. Apart from ${ }^{12} \mathrm{CO}(2-1)$ no other lines have been taken into consideration as they account for a much lower contribution (Braine et al. 1995). The corrected flux densities of the central channel at the MRT, the sum of all channels of the array with $S / N \geq 3$ and the single-channel at the SEST are given in Cols. (6), (7) and (10), respectively.

Figure 2 shows the fractional line contamination versus the projected beam size. Opposite to Fig. 1 no dependency is apparent. Both, $\mathrm{CO}$ and $1300 \mu \mathrm{m}$ continuum, refer to the same 

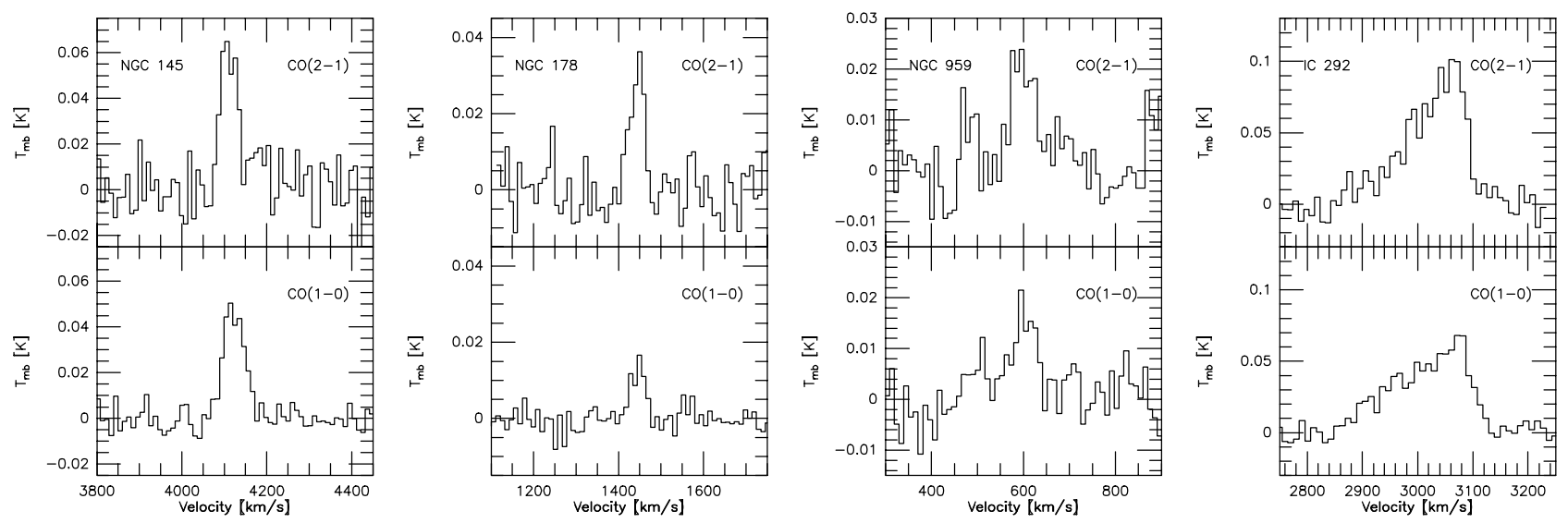

Fig. 3. ${ }^{12} \mathrm{CO}(1-0)$ and (2-1) spectra from MRT for NGC 145, NGC 178, NGC 959 and IC 292. The full version of Fig. 3 is available at http://www. edpsciences.org.
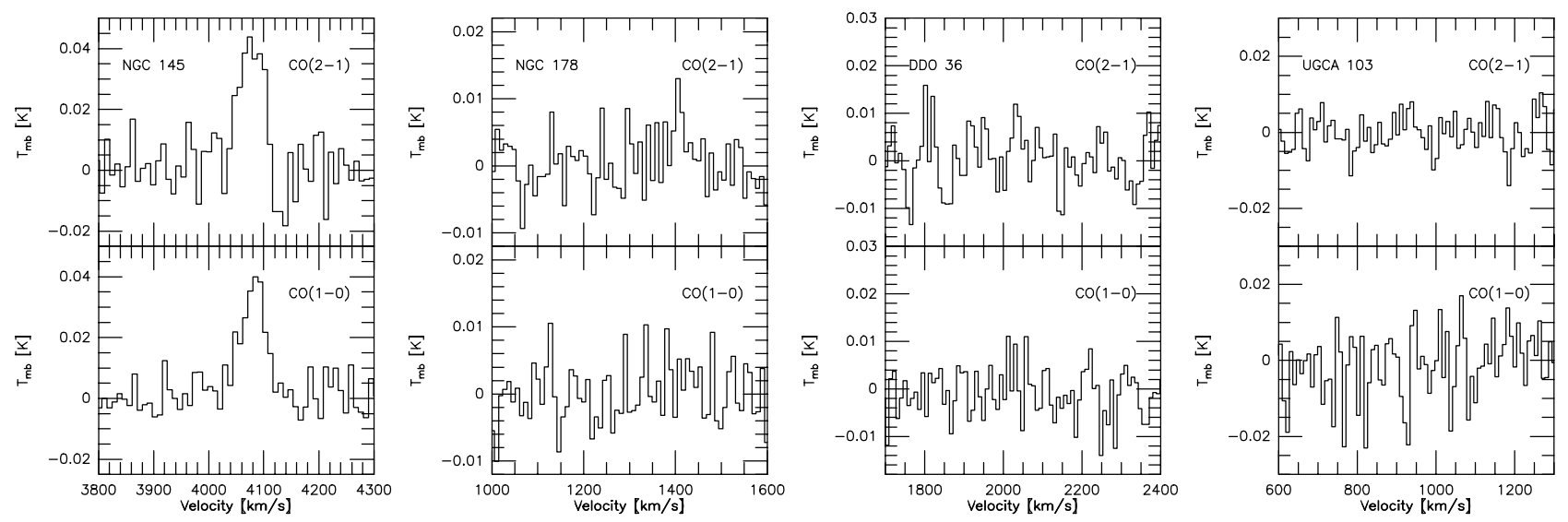

Fig. 4. ${ }^{12} \mathrm{CO}(1-0)$ and (2-1) spectra from SEST for NGC 145, NGC 178, DDO 36 and UGCA 103. The full version of Fig. 4 is available at http://www . edpsciences.org.

beam size. Nevertheless, a systematic difference in the spatial distribution of ${ }^{12} \mathrm{CO}$ and dust would be reflected in the plot. Again we refer to Paper II for a more precise discussion of this topic. The scatter in the diagram cannot be attributed to measurement errors alone and has to be intrinsic to the galaxies.

\subsection{HI and optical data}

We were able to independently determine the radial velocity using the ${ }^{12} \mathrm{CO}$ observations resulting in new distance values for a set of galaxies for which the spectra can be fit with a single Gaussian component. The adopted distances given in Tables 13 were used to newly derive H I and optical properties.

To estimate the amount of atomic hydrogen in the sample galaxies the H I line magnitudes $m_{21}$ have been taken from the RC3. The H I line magnitude is defined as

$m_{21}=16.6-2.5 \log S_{\mathrm{HI}}$,

where the H I flux $S_{\mathrm{HI}}$ is in units of $10^{-22} \mathrm{~W} \mathrm{~m}^{-2}$. The values of $S_{\mathrm{HI}}$ for IC 292 and NGC 7732 are taken from Schneider et al. (1992) corrected and mirrored according to Melisse \& Israel (1993a). No H I data are available for NGC 4810.
From this the apparent $\mathrm{HI}$ mass in solar units $M_{\mathrm{HI}}$ corrected for redshift $z$ is given by

$\log M_{\mathrm{HI}}=\log S_{\mathrm{HI}}+\log (1+z)+2 \log D+5.696$,

where the distance $D$ is in units of Mpc (de Vaucouleurs et al. 1991). The self-absorption of the H I flux as a function of axis ratio is still an object of debate. To retrieve the true $\mathrm{H} \mathrm{I}$ mass, we have applied the suggestion of de Vaucouleurs et al. (1991) to correct the H I magnitude by $m_{21}^{0}=m_{21}-0.5 \log R_{25}$ for all galaxies with morphological type parameters $T \geq 1$, where the major-to-minor axis ratio $R_{25}$ is set to 10.0 for all galaxies with $R_{25} \geq 10.0$. The resulting values for the H I mass are given in Col. (9) of Tables 1-3.

The angular size (major and minor axis) of the galaxies at the 25 th mag $\operatorname{arcsec}^{-2}$ isophote as taken from the NED is mirrored in Col. (6) of Tables 1-3. This enables the calculation of the absolute linear diameter which is listed in Col. (7) of the same tables.

To derive the absolute blue magnitude $M_{\mathrm{B}}$, the total blue magnitude $B_{\mathrm{T}}^{0}$ corrected for galactic absorption, internal absorption and redshift has been extracted from the RC3. The values for UGCA 116 and NGC 4810 are taken from Tully (1988) and the value for NGC 2719 is taken from Kraan-Korteweg (1986). Using the adopted distances the 
Table 5. Results of the ${ }^{12} \mathrm{CO}$ observations from MRT and SEST.

\begin{tabular}{|c|c|c|c|c|c|c|c|c|c|c|c|}
\hline \multirow[b]{2}{*}{ Name } & \multirow[b]{2}{*}{${ }^{12} \mathrm{CO}$} & \multicolumn{5}{|c|}{ MRT } & \multicolumn{5}{|c|}{ SEST } \\
\hline & & $\begin{array}{c}v_{\mathrm{LSR}} \\
{\left[\mathrm{km} \mathrm{s}^{-1}\right]} \\
(3)\end{array}$ & $\begin{array}{c}\mathrm{d} v \\
{\left[\mathrm{~km} \mathrm{~s}^{-1}\right]} \\
(4)\end{array}$ & $\begin{array}{c}T_{\mathrm{mb}} \\
{[\mathrm{mK}]} \\
(5)\end{array}$ & $\begin{array}{c}\sigma_{\mathrm{rms}} \\
{[\mathrm{mK}]} \\
(6)\end{array}$ & $\begin{array}{c}I_{12} \mathrm{CO} \\
{\left[\mathrm{K} \mathrm{km} \mathrm{s}^{-1}\right]} \\
(7)\end{array}$ & $\begin{array}{c}v_{\mathrm{LSR}} \\
{\left[\mathrm{km} \mathrm{s}^{-1}\right]} \\
(8)\end{array}$ & $\begin{array}{c}\mathrm{d} v \\
{\left[\mathrm{~km} \mathrm{~s}^{-1}\right]} \\
(9)\end{array}$ & $\begin{array}{c}T_{\mathrm{mb}} \\
{[\mathrm{mK}]} \\
(10)\end{array}$ & $\begin{array}{c}\sigma_{\mathrm{rms}} \\
{[\mathrm{mK}]} \\
(11)\end{array}$ & $\begin{array}{c}I_{12} \mathrm{CO}^{-1} \\
{\left[\mathrm{~K} \mathrm{~km} \mathrm{~s}^{-1}\right]} \\
(12)\end{array}$ \\
\hline$(1)$ & & \multicolumn{10}{|c|}{ Sdm / Sm } \\
\hline \multirow[t]{2}{*}{ NGC 145} & $1-0$ & 4122 & 58 & 49.6 & 4.7 & $3.05 \pm 0.19$ & 4081 & 53 & 38.1 & 4.9 & $2.14 \pm 0.17$ \\
\hline & $2-1$ & 4111 & 45 & 65.1 & 10.7 & $2.87 \pm 0.32$ & 4076 & 48 & 45.8 & 8.3 & $2.26 \pm 0.27$ \\
\hline \multirow[t]{2}{*}{ NGC 178} & $1-0$ & 1446 & 38 & 14.8 & 2.8 & $0.60 \pm 0.09$ & - & - & - & 4.5 & $<0.49$ \\
\hline & $2-1$ & 1445 & 37 & 34.0 & 6.2 & $1.29 \pm 0.18$ & - & - & - & 4.2 & $<0.46$ \\
\hline \multirow[t]{2}{*}{ NGC 959} & $1-0$ & 601 & 63 & 16.5 & 4.8 & $1.11 \pm 0.21$ & & & & & \\
\hline & $2-1$ & 599 & 59 & 21.2 & 6.3 & $1.29 \pm 0.24$ & & & & & \\
\hline \multirow[t]{4}{*}{ IC 292} & $1-0$ & 2994 & 152 & 42.4 & 5.8 & $9.32 \pm 0.39$ & & & & & \\
\hline & & 3074 & 55 & 45.5 & 5.8 & & & & & & \\
\hline & $2-1$ & 3014 & 126 & 60.0 & 8.2 & $11.00 \pm 0.59$ & & & & & \\
\hline & & 3067 & 46 & 63.4 & 8.2 & & & & & & \\
\hline \multirow[t]{2}{*}{ DDO 36} & $1-0$ & - & - & - & 4.2 & $<0.37$ & - & - & - & 4.6 & $<0.38$ \\
\hline & $2-1$ & - & - & - & 7.2 & $<0.62$ & - & - & - & 6.7 & $<0.56$ \\
\hline \multirow[t]{2}{*}{ UGCA 103} & $1-0$ & & & & & & - & - & - & 8.8 & $<1.22$ \\
\hline & $2-1$ & & & & & & - & - & - & 5.5 & $<0.77$ \\
\hline \multirow[t]{2}{*}{ NGC 1879} & $1-0$ & - & - & - & 6.2 & $<0.92$ & - & - & - & 13.6 & $<1.88$ \\
\hline & $2-1$ & 1219 & 56 & 17.2 & 6.1 & $0.90 \pm 0.18$ & - & - & - & 12.8 & $<1.78$ \\
\hline \multirow[t]{2}{*}{ UGC 4151} & $1-0$ & 2297 & 91 & 32.6 & 2.7 & $3.05 \pm 0.12$ & & & & & \\
\hline & $2-1$ & 2297 & 77 & 39.5 & 5.1 & $3.04 \pm 0.21$ & & & & & \\
\hline \multirow[t]{2}{*}{ NGC 2537} & $1-0$ & 443 & 56 & 15.7 & 3.1 & $0.91 \pm 0.13$ & & & & & \\
\hline & $2-1$ & 447 & 47 & 19.3 & 4.5 & $0.94 \pm 0.15$ & & & & & \\
\hline \multirow[t]{2}{*}{ NGC 2730} & $1-0$ & 3847 & 97 & 18.8 & 2.7 & $1.95 \pm 0.14$ & 3760 & 148 & 8.8 & 2.9 & $1.37 \pm 0.24$ \\
\hline & $2-1$ & 3846 & 69 & 16.3 & 5.4 & $1.21 \pm 0.23$ & 3743 & 103 & 11.2 & 3.5 & $1.20 \pm 0.18$ \\
\hline \multirow[t]{2}{*}{ NGC 3057} & $1-0$ & - & - & - & 3.0 & $<0.45$ & & & & & \\
\hline & $2-1$ & - & - & - & 5.1 & $<0.75$ & & & & & \\
\hline \multirow[t]{2}{*}{ NGC 3246} & $1-0$ & - & - & - & 3.5 & $<0.71$ & - & - & - & 3.9 & $<0.73$ \\
\hline & $2-1$ & - & - & - & 4.0 & $<0.79$ & - & - & - & 4.7 & $<0.89$ \\
\hline \multirow[t]{2}{*}{ NGC 3445} & $1-0$ & 2045 & 41 & 21.0 & 3.0 & $0.94 \pm 0.10$ & & & & & \\
\hline & $2-1$ & 2048 & 23 & 24.6 & 7.2 & $0.50 \pm 0.18$ & & & & & \\
\hline \multirow[t]{2}{*}{ NGC 3659} & $1-0$ & 1303 & 86 & 44.0 & 4.7 & $3.92 \pm 0.21$ & - & - & - & 6.1 & $<1.15$ \\
\hline & $2-1$ & 1311 & 67 & 46.3 & 5.7 & $3.25 \pm 0.25$ & - & - & - & 3.6 & $<0.68$ \\
\hline \multirow[t]{2}{*}{ NGC 3664} & $1-0$ & 1383 & 39 & 6.6 & 2.1 & $0.29 \pm 0.08$ & - & - & - & 6.5 & $<0.79$ \\
\hline & $2-1$ & 1385 & 14 & 16.9 & 4.2 & $0.27 \pm 0.08$ & - & - & - & 5.5 & $<0.67$ \\
\hline \multirow[t]{4}{*}{ NGC 3839} & $1-0$ & 5827 & 79 & 28.5 & 2.6 & $5.47 \pm 0.20$ & & & & & \\
\hline & & 5926 & 66 & 21.4 & 2.6 & & & & & & \\
\hline & & 6018 & 71 & 19.2 & 2.6 & & & & & & \\
\hline & $2-1$ & - & - & - & 9.1 & $<2.06$ & & & & & \\
\hline \multirow[t]{2}{*}{ NGC 3879} & $1-0$ & - & - & - & 3.6 & $<0.66$ & & & & & \\
\hline & $2-1$ & - & - & - & 6.9 & $<1.24$ & & & & & \\
\hline
\end{tabular}

absolute blue magnitude of the galaxies has been determined following

$M_{\mathrm{B}}=B_{\mathrm{T}}^{0}-5 \log D-25$, where the distance $D$ is in units of Mpc (de Vaucouleurs et al. 1991). The results are given in Col. (10) of Tables 1-3.

Acknowledgements. Part of this project was supported by the Deutsche Forschungsgemeinschaft (DFG) via the Graduiertenkolleg The Magellanic Clouds and other Dwarf Galaxies. 
Table 5. continued.

\begin{tabular}{|c|c|c|c|c|c|c|c|c|c|c|c|}
\hline \multirow[b]{2}{*}{ Name } & \multirow[b]{2}{*}{${ }^{12} \mathrm{CO}$} & \multicolumn{5}{|c|}{ MRT } & \multicolumn{5}{|c|}{ SEST } \\
\hline & & $\begin{array}{c}v_{\mathrm{LSR}} \\
{\left[\mathrm{km} \mathrm{s}^{-1}\right]} \\
(3)\end{array}$ & $\begin{array}{c}\mathrm{d} v \\
{\left[\mathrm{~km} \mathrm{~s}^{-1}\right]} \\
(4)\end{array}$ & $\begin{array}{c}T_{\mathrm{mb}} \\
{[\mathrm{mK}]} \\
(5)\end{array}$ & $\begin{array}{c}\sigma_{\mathrm{rms}} \\
{[\mathrm{mK}]} \\
(6)\end{array}$ & $\begin{array}{c}I_{12} \mathrm{CO}^{2} \\
{\left[\mathrm{~K} \mathrm{~km} \mathrm{~s}^{-1}\right]} \\
(7)\end{array}$ & $\begin{array}{c}v_{\mathrm{LSR}} \\
{\left[\mathrm{km} \mathrm{s}^{-1}\right]} \\
(8)\end{array}$ & $\begin{array}{c}\mathrm{d} v \\
{\left[\mathrm{~km} \mathrm{~s}^{-1}\right]} \\
(9)\end{array}$ & $\begin{array}{c}T_{\mathrm{mb}} \\
{[\mathrm{mK}]} \\
(10)\end{array}$ & $\begin{array}{c}\sigma_{\mathrm{rms}} \\
{[\mathrm{mK}]} \\
(11)\end{array}$ & $\begin{array}{c}I_{12} \mathrm{CO} \\
{\left[\mathrm{K} \mathrm{km} \mathrm{s}^{-1}\right]} \\
(12)\end{array}$ \\
\hline \multirow[t]{3}{*}{ NGC 3991} & $1-0$ & 3210 & 96 & 16.7 & 3.3 & $1.63 \pm 0.15$ & & & & & \\
\hline & $2-1$ & 3206 & 42 & 45.0 & 4.7 & $2.79 \pm 0.19$ & & & & & \\
\hline & & 3255 & 31 & 21.4 & 4.7 & & & & & & \\
\hline \multirow[t]{2}{*}{ NGC 4234} & $1-0$ & 2051 & 47 & 58.6 & 11.7 & $2.85 \pm 0.44$ & - & - & - & 15.8 & $<2.25$ \\
\hline & $2-1$ & - & - & - & 14.1 & $<2.09$ & - & - & - & 15.9 & $<2.29$ \\
\hline \multirow[t]{2}{*}{ NGC 4299} & $1-0$ & 222 & 44 & 13.6 & 4.1 & $0.52 \pm 0.16$ & & & & & \\
\hline & $2-1$ & - & - & - & 10.3 & $<1.53$ & & & & & \\
\hline \multirow[t]{2}{*}{ NGC 4523} & $1-0$ & - & - & - & 3.8 & $<0.57$ & & & & & \\
\hline & $2-1$ & - & - & - & 5.4 & $<0.79$ & & & & & \\
\hline \multirow[t]{2}{*}{ IC 3521} & $1-0$ & 586 & 55 & 72.7 & 4.6 & $4.30 \pm 0.17$ & - & - & - & 10.7 & $<1.42$ \\
\hline & $2-1$ & 584 & 44 & 102.2 & 13.4 & $4.75 \pm 0.45$ & 588 & 52 & 41.8 & 8.2 & $2.09 \pm 0.29$ \\
\hline \multirow[t]{2}{*}{ NGC 4625} & $1-0$ & 620 & 42 & 84.7 & 5.5 & $3.61 \pm 0.17$ & & & & & \\
\hline & $2-1$ & 627 & 33 & 119.8 & 12.6 & $4.31 \pm 0.37$ & & & & & \\
\hline \multirow[t]{2}{*}{ DDO 180} & $1-0$ & 1296 & 39 & 33.0 & 3.9 & $1.38 \pm 0.14$ & & & & & \\
\hline & $2-1$ & 1297 & 32 & 33.1 & 6.3 & $1.09 \pm 0.17$ & & & & & \\
\hline \multirow[t]{4}{*}{ NGC 5433} & $1-0$ & 4233 & 126 & 48.9 & 4.8 & $20.30 \pm 0.54$ & & & & & \\
\hline & & 4385 & 315 & 42.0 & 4.8 & & & & & & \\
\hline & $2-1$ & 4298 & 160 & 65.2 & 12.6 & $19.31 \pm 1.05$ & & & & & \\
\hline & & 4214 & 97 & 82.3 & 12.6 & & & & & & \\
\hline \multirow[t]{2}{*}{ NGC 5486} & $1-0$ & - & - & - & 2.5 & $<0.44$ & & & & & \\
\hline & $2-1$ & 1368 & 79 & 9.5 & 3.1 & $0.82 \pm 0.16$ & & & & & \\
\hline \multirow[t]{4}{*}{ NGC 6570} & $1-0$ & 2246 & 95 & 40.0 & 3.8 & $6.38 \pm 0.22$ & 2200 & 28 & 16.8 & 5.1 & $2.28 \pm 0.27$ \\
\hline & & 2347 & 94 & 26.4 & 3.8 & & 2309 & 138 & 13.7 & 5.1 & \\
\hline & $2-1$ & 2279 & 105 & 59.2 & 5.5 & $7.93 \pm 0.32$ & 2198 & 32 & 9.3 & 5.5 & $2.63 \pm 0.32$ \\
\hline & & 2366 & 41 & 31.6 & 5.5 & & 2329 & 117 & 18.8 & 5.5 & \\
\hline \multirow[t]{2}{*}{ NGC 7162A } & $1-0$ & & & & & & - & - & - & 3.4 & $<0.46$ \\
\hline & $2-1$ & & & & & & - & - & - & 5.5 & $<0.75$ \\
\hline \multirow[t]{3}{*}{ UGC 12082} & $1-0$ & - & - & - & 1.7 & $<0.18$ & & & & & \\
\hline & $2-1$ & - & - & - & 3.0 & $<0.32$ & & & & & \\
\hline & & \multicolumn{10}{|c|}{ Im / I0 / Irr } \\
\hline \multirow[t]{2}{*}{ ARP 004} & $1-0$ & - & - & - & 3.8 & $<0.52$ & & & & & \\
\hline & $2-1$ & - & - & - & 7.2 & $<0.95$ & & & & & \\
\hline \multirow[t]{2}{*}{ NGC 899} & $1-0$ & - & - & - & 4.3 & $<0.63$ & - & - & - & 3.4 & $<0.46$ \\
\hline & $2-1$ & - & - & - & 9.4 & $<1.34$ & - & - & - & 4.1 & $<0.56$ \\
\hline \multirow[t]{2}{*}{ NGC 1140} & $1-0$ & 1473 & 42 & 18.9 & 4.3 & $0.97 \pm 0.17$ & - & - & - & 6.5 & $<1.14$ \\
\hline & $2-1$ & 1475 & 55 & 46.4 & 6.1 & $2.82 \pm 0.22$ & - & - & - & 7.4 & $<1.32$ \\
\hline \multirow[t]{2}{*}{ NGC 1602} & $1-0$ & & & & & & - & - & - & 3.3 & $<0.37$ \\
\hline & $2-1$ & & & & & & - & - & - & 2.3 & $<0.26$ \\
\hline
\end{tabular}


Table 5. continued.

\begin{tabular}{|c|c|c|c|c|c|c|c|c|c|c|c|}
\hline \multirow[b]{2}{*}{ Name } & \multirow[b]{2}{*}{${ }^{12} \mathrm{CO}$} & \multicolumn{5}{|c|}{ MRT } & \multicolumn{5}{|c|}{ SEST } \\
\hline & & $\begin{array}{c}v_{\mathrm{LSR}} \\
{\left[\mathrm{km} \mathrm{s}^{-1}\right]} \\
(3)\end{array}$ & $\begin{array}{c}\mathrm{d} v \\
{\left[\mathrm{~km} \mathrm{~s}^{-1}\right]} \\
(4)\end{array}$ & $\begin{array}{c}T_{\mathrm{mb}} \\
{[\mathrm{mK}]} \\
(5)\end{array}$ & $\begin{array}{c}\sigma_{\mathrm{rms}} \\
{[\mathrm{mK}]} \\
(6)\end{array}$ & $\begin{array}{c}I_{12} \mathrm{CO} \\
{\left[\mathrm{K} \mathrm{km} \mathrm{s}^{-1}\right]} \\
(7)\end{array}$ & $\begin{array}{c}v_{\mathrm{LSR}} \\
{\left[\mathrm{km} \mathrm{s}^{-1}\right]} \\
(8)\end{array}$ & $\begin{array}{c}\mathrm{d} v \\
{\left[\mathrm{~km} \mathrm{~s}^{-1}\right]} \\
(9)\end{array}$ & $\begin{array}{c}T_{\mathrm{mb}} \\
{[\mathrm{mK}]} \\
(10)\end{array}$ & $\begin{array}{c}\sigma_{\mathrm{rms}} \\
{[\mathrm{mK}]} \\
(11)\end{array}$ & $\begin{array}{c}I_{12} \mathrm{CO} \\
{\left[\mathrm{K} \mathrm{km} \mathrm{s}^{-1}\right]} \\
(12)\end{array}$ \\
\hline \multirow[t]{2}{*}{ NGC 1569} & $1-0$ & -71 & 31 & 30.3 & 3.8 & $1.08 \pm 0.10$ & & & & & \\
\hline & $2-1$ & -70 & 22 & 55.4 & 5.5 & $1.38 \pm 0.14$ & & & & & \\
\hline \multirow[t]{2}{*}{ UGC 3234} & $1-0$ & - & - & - & 3.5 & $<0.71$ & - & - & - & 5.2 & $<0.73$ \\
\hline & $2-1$ & - & - & - & 4.0 & $<0.79$ & - & - & - & 5.4 & $<0.77$ \\
\hline \multirow[t]{2}{*}{ UGCA 105} & $1-0$ & - & - & - & 2.1 & $<0.30$ & & & & & \\
\hline & $2-1$ & 107 & 14 & 11.2 & 3.0 & $0.31 \pm 0.06$ & & & & & \\
\hline \multirow[t]{2}{*}{ NGC 2366} & $1-0$ & - & - & - & 2.6 & $<0.34$ & & & & & \\
\hline & $2-1$ & - & - & - & 3.5 & $<0.45$ & & & & & \\
\hline \multirow[t]{4}{*}{ NGC 2415} & $1-0$ & 3750 & 88 & 89.8 & 5.7 & $12.78 \pm 0.34$ & & & & & \\
\hline & & 3833 & 72 & 58.7 & 5.7 & & & & & & \\
\hline & $2-1$ & 3730 & 79 & 110.0 & 10.5 & $16.70 \pm 0.61$ & & & & & \\
\hline & & 3791 & 112 & 64.9 & 10.5 & & & & & & \\
\hline \multirow[t]{2}{*}{ NGC 2719} & $1-0$ & - & - & - & 1.4 & $<0.34$ & & & & & \\
\hline & $2-1$ & - & - & - & 3.5 & $<0.81$ & & & & & \\
\hline \multirow[t]{2}{*}{ NGC 2915} & $1-0$ & & & & & & - & - & - & 8.8 & $<1.28$ \\
\hline & $2-1$ & & & & & & - & - & - & 4.9 & $<0.72$ \\
\hline \multirow[t]{2}{*}{ NGC 3026} & $1-0$ & - & - & - & 2.6 & $<0.48$ & & & & & \\
\hline & $2-1$ & - & - & - & 11.6 & $<2.10$ & & & & & \\
\hline \multirow[t]{2}{*}{ NGC 3077} & $1-0$ & -1 & 32 & 158.0 & 10.2 & $5.32 \pm 0.35$ & & & & & \\
\hline & $2-1$ & -2 & 23 & 195.9 & 18.1 & $4.77 \pm 0.41$ & & & & & \\
\hline \multirow[t]{4}{*}{ UGC 5720} & $1-0$ & 1405 & 31 & 22.4 & 3.2 & $3.99 \pm 0.15$ & & & & & \\
\hline & & 1456 & 67 & 45.3 & 3.2 & & & & & & \\
\hline & $2-1$ & 1404 & 32 & 51.4 & 5.7 & $4.98 \pm 0.26$ & & & & & \\
\hline & & 1460 & 57 & 55.0 & 5.7 & & & & & & \\
\hline \multirow[t]{2}{*}{ NGC 3396} & $1-0$ & 1683 & 46 & 56.1 & 3.5 & $2.87 \pm 0.14$ & & & & & \\
\hline & $2-1$ & 1682 & 40 & 92.8 & 10.2 & $4.39 \pm 0.36$ & & & & & \\
\hline \multirow[t]{2}{*}{ UGC 6345} & $1-0$ & - & - & - & 3.8 & $<0.56$ & & & & & \\
\hline & $2-1$ & - & - & - & 6.7 & $<0.96$ & & & & & \\
\hline \multirow[t]{2}{*}{ NGC 3738} & $1-0$ & 224 & 22 & 19.9 & 2.3 & $0.51 \pm 0.07$ & & & & & \\
\hline & $2-1$ & 227 & 25 & 23.6 & 4.6 & $0.58 \pm 0.11$ & & & & & \\
\hline \multirow[t]{2}{*}{ NGC 4032} & $1-0$ & 1271 & 43 & 19.6 & 3.1 & $0.86 \pm 0.11$ & & & & & \\
\hline & $2-1$ & 1264 & 43 & 19.3 & 3.3 & $0.83 \pm 0.09$ & & & & & \\
\hline \multirow[t]{2}{*}{ NGC 4190} & $1-0$ & - & - & - & 6.3 & $<0.64$ & & & & & \\
\hline & $2-1$ & - & - & - & 18.4 & $<1.83$ & & & & & \\
\hline \multirow[t]{6}{*}{ NGC 4194} & $1-0$ & 2480 & 86 & 75.9 & 3.4 & $29.26 \pm 0.26$ & & & & & \\
\hline & & 2569 & 129 & 143.1 & 3.4 & & & & & & \\
\hline & & 2683 & 44 & 55.3 & 3.4 & & & & & & \\
\hline & $2-1$ & 2475 & 104 & 138.7 & 7.6 & $45.45 \pm 0.65$ & & & & & \\
\hline & & 2570 & 112 & 214.9 & 7.6 & & & & & & \\
\hline & & 2680 & 43 & 104.7 & 7.6 & & & & & & \\
\hline
\end{tabular}


Table 5. continued.

\begin{tabular}{|c|c|c|c|c|c|c|c|c|c|c|c|}
\hline \multirow[b]{2}{*}{ Name } & \multirow[b]{2}{*}{${ }^{12} \mathrm{CO}$} & \multicolumn{5}{|c|}{ MRT } & \multicolumn{5}{|c|}{ SEST } \\
\hline & & $\begin{array}{c}v_{\mathrm{LSR}} \\
{\left[\mathrm{km} \mathrm{s}^{-1}\right]} \\
(3)\end{array}$ & $\begin{array}{c}\mathrm{d} v \\
{\left[\mathrm{~km} \mathrm{~s}^{-1}\right]} \\
(4)\end{array}$ & $\begin{array}{c}T_{\mathrm{mb}} \\
{[\mathrm{mK}]} \\
(5)\end{array}$ & $\begin{array}{c}\sigma_{\mathrm{rms}} \\
{[\mathrm{mK}]} \\
(6)\end{array}$ & $\begin{array}{c}I_{12} \mathrm{CO} \\
{\left[\mathrm{K} \mathrm{km} \mathrm{s}^{-1}\right]} \\
\text { (7) }\end{array}$ & $\begin{array}{c}v_{\mathrm{LSR}} \\
{\left[\mathrm{km} \mathrm{s}^{-1}\right]} \\
(8)\end{array}$ & $\begin{array}{c}\mathrm{d} v \\
{\left[\mathrm{~km} \mathrm{~s}^{-1}\right]} \\
(9)\end{array}$ & $\begin{array}{c}T_{\mathrm{mb}} \\
{[\mathrm{mK}]} \\
(10)\end{array}$ & $\begin{array}{c}\sigma_{\mathrm{rms}} \\
{[\mathrm{mK}]} \\
(11)\end{array}$ & $\begin{array}{c}{ }^{I_{12}} \mathrm{CO} \\
{\left[\mathrm{K} \mathrm{km} \mathrm{s}^{-1}\right]} \\
(12)\end{array}$ \\
\hline \multirow[t]{2}{*}{ NGC 4485} & $1-0$ & - & - & - & 3.1 & $<0.50$ & & & & & \\
\hline & $2-1$ & - & - & - & 8.1 & $<1.28$ & & & & & \\
\hline \multirow[t]{2}{*}{ UGC 7690} & $1-0$ & - & - & - & 3.1 & $<0.38$ & & & & & \\
\hline & $2-1$ & - & - & - & 3.3 & $<0.40$ & & & & & \\
\hline \multirow[t]{2}{*}{ IC 3476} & $1-0$ & -144 & 46 & 55.9 & 4.6 & $2.80 \pm 0.16$ & & & & & \\
\hline & $2-1$ & -147 & 40 & 76.2 & 12.5 & $3.60 \pm 0.44$ & & & & & \\
\hline \multirow[t]{2}{*}{ NGC 4532} & $1-0$ & 2044 & 61 & 37.0 & 3.5 & $2.34 \pm 0.14$ & - & - & - & 5.5 & $<0.99$ \\
\hline & $2-1$ & 2042 & 49 & 62.1 & 7.3 & $3.25 \pm 0.26$ & 2037 & 66 & 20.3 & 4.1 & $1.39 \pm 0.15$ \\
\hline \multirow[t]{2}{*}{ NGC 4630} & $1-0$ & 735 & 58 & 66.2 & 7.0 & $3.86 \pm 0.33$ & & & & & \\
\hline & $2-1$ & 737 & 72 & 70.0 & 19.8 & $4.84 \pm 0.81$ & & & & & \\
\hline \multirow[t]{2}{*}{ NGC 4810} & $1-0$ & - & - & - & 3.0 & $<0.029 \sqrt{\Delta v}$ & & & & & \\
\hline & $2-1$ & - & - & - & 3.7 & $<0.035 \sqrt{\Delta v}$ & & & & & \\
\hline \multirow[t]{2}{*}{ NGC 5408} & $1-0$ & & & & & & - & - & - & 4.9 & $<0.56$ \\
\hline & $2-1$ & & & & & & - & - & - & 4.1 & $<0.47$ \\
\hline \multirow[t]{2}{*}{ NGC 5464} & $1-0$ & & & & & & - & - & - & 5.3 & $<0.88$ \\
\hline & $2-1$ & & & & & & - & - & - & 4.5 & $<0.75$ \\
\hline \multirow[t]{2}{*}{ ARP 261} & $1-0$ & - & - & - & 4.0 & $<0.68$ & - & - & - & 5.7 & $<0.89$ \\
\hline & $2-1$ & - & - & - & 8.0 & $<1.30$ & - & - & - & 6.2 & $<0.98$ \\
\hline \multirow[t]{2}{*}{ NGC 5798} & $1-0$ & 1806 & 93 & 10.7 & 2.3 & $1.05 \pm 0.12$ & & & & & \\
\hline & $2-1$ & 1796 & 88 & 15.9 & 3.2 & $1.36 \pm 0.16$ & & & & & \\
\hline \multirow[t]{2}{*}{ IC 4662} & $1-0$ & & & & & & - & - & - & 5.5 & $<0.70$ \\
\hline & $2-1$ & & & & & & - & - & - & 3.2 & $<0.42$ \\
\hline \multirow[t]{3}{*}{ NGC 7292} & $1-0$ & 1010 & 18 & 23.0 & 5.0 & $0.38 \pm 0.14$ & - & - & - & 9.4 & $<1.05$ \\
\hline & $2-1$ & - & - & - & 2.8 & $<0.33$ & - & - & - & 7.2 & $<0.81$ \\
\hline & & \multicolumn{10}{|c|}{ complementary galaxies } \\
\hline \multirow[t]{2}{*}{ NGC 1012} & $1-0$ & 968 & 68 & 40.5 & 7.3 & $2.95 \pm 0.30$ & & & & & \\
\hline & $2-1$ & 964 & 59 & 105.0 & 8.3 & $6.35 \pm 0.29$ & & & & & \\
\hline \multirow[t]{2}{*}{ UGCA 116} & $1-0$ & 752 & 28 & 6.1 & 1.8 & $0.23 \pm 0.05$ & - & - & - & 6.1 & $<0.92$ \\
\hline & $2-1$ & 750 & 39 & 15.7 & 2.2 & $0.69 \pm 0.07$ & - & - & - & 6.6 & $<1.01$ \\
\hline \multirow[t]{2}{*}{ NGC 2976} & $1-0$ & -4 & 31 & 121.0 & 5.3 & $4.12 \pm 0.17$ & & & & & \\
\hline & $2-1$ & -1 & 22 & 90.4 & 13.2 & $1.98 \pm 0.30$ & & & & & \\
\hline \multirow[t]{2}{*}{ UGCA 247} & $1-0$ & & & & & & 1918 & 55 & 18.3 & 3.4 & $1.13 \pm 0.13$ \\
\hline & $2-1$ & & & & & & 1928 & 41 & 13.9 & 3.1 & $0.62 \pm 0.10$ \\
\hline \multirow[t]{2}{*}{ NGC 7107} & $1-0$ & & & & & & - & - & - & 2.3 & $<0.27$ \\
\hline & $2-1$ & & & & & & - & - & - & 2.9 & $<0.34$ \\
\hline \multirow[t]{2}{*}{ NGC 7732} & $1-0$ & 2925 & 87 & 21.6 & 7.0 & $1.96 \pm 0.39$ & 2921 & 79 & 7.7 & 2.6 & $0.58 \pm 0.14$ \\
\hline & $2-1$ & 2956 & 130 & 46.1 & 10.9 & $5.92 \pm 0.57$ & 2923 & 98 & 9.1 & 3.0 & $0.95 \pm 0.13$ \\
\hline
\end{tabular}


Table 6. Results of the continuum observations from MRT and SEST.

\begin{tabular}{|c|c|c|c|c|c|c|c|c|c|}
\hline \multirow[b]{2}{*}{ Name } & \multicolumn{6}{|c|}{ MRT } & \multicolumn{3}{|c|}{ SEST } \\
\hline & $\begin{array}{c}S_{1300 \mu \mathrm{m}} \\
{[\mathrm{mJy}]}\end{array}$ & $\begin{array}{c}S_{{ }^{12} \mathrm{CO}} / S_{1300 \mu \mathrm{m}} \\
{[\%]}\end{array}$ & $\begin{array}{c}\Sigma S_{1300 \mu \mathrm{m}} \\
{[\mathrm{mJy}]}\end{array}$ & $\begin{array}{l}\text { Number } \\
\text { of Chans. }\end{array}$ & $\begin{array}{c}S_{\text {dust }} \\
{[\mathrm{mJy}]}\end{array}$ & $\begin{array}{l}\Sigma S_{\text {dust }} \\
{[\mathrm{mJy}]}\end{array}$ & $\begin{array}{c}S_{1300 \mu \mathrm{m}} \\
{[\mathrm{mJy}]}\end{array}$ & $\begin{array}{c}S_{12 \mathrm{CO}} / S_{1300 \mu \mathrm{m}} \\
{[\%]}\end{array}$ & $\begin{array}{c}S_{\text {dust }} \\
{[\mathrm{mJy}]}\end{array}$ \\
\hline$(1)$ & & & & & & & & & \\
\hline & \multicolumn{9}{|c|}{ Sdm / Sm } \\
\hline NGC 145 & $<12.9$ & $>2$ & - & 0 & $<11.6$ & - & & & \\
\hline NGC 959 & $<2.4$ & $>4$ & - & 0 & $<2.2$ & - & & & \\
\hline IC 292 & $2.5 \pm 0.6$ & 36 & $2.5 \pm 0.6$ & 1 & $1.6 \pm 0.5$ & $1.6 \pm 0.5$ & & & \\
\hline UGCA 103 & & & & & & & $<12.5$ & - & $<11.2$ \\
\hline NGC 1879 & & & & & & & $<8.4$ & - & $<7.5$ \\
\hline NGC 2537 & $<4.8$ & $>2$ & $6.5 \pm 1.4$ & 1 & $<4.3$ & $5.8 \pm 1.5$ & & & \\
\hline NGC 2730 & $<2.8$ & $>4$ & - & 0 & $<2.5$ & - & & & \\
\hline NGC 3246 & $<6.0$ & - & - & 0 & $<5.4$ & - & & & \\
\hline NGC 3659 & $<6.4$ & $>4$ & - & 0 & $<5.7$ & - & $<12.6$ & - & $<11.2$ \\
\hline NGC 3664 & $<2.4$ & $>1$ & - & 0 & $<2.2$ & - & & & \\
\hline NGC 3839 & $5.8 \pm 1.7$ & $<2$ & $5.8 \pm 1.7$ & 1 & $5.7 \pm 1.6$ & $5.7 \pm 1.6$ & & & \\
\hline NGC 3991 & $<6.6$ & $>4$ & - & 0 & $<5.9$ & - & & & \\
\hline NGC 4299 & $<4.6$ & - & $6.8 \pm 2.0$ & 1 & $<4.1$ & $6.1 \pm 1.9$ & $<7.2$ & - & $<6.5$ \\
\hline IC 3521 & $3.6 \pm 0.7$ & 11 & $24.3 \pm 6.4$ & 7 & $3.2 \pm 0.7$ & $21.7 \pm 5.8$ & & & \\
\hline NGC 4625 & $3.1 \pm 0.8$ & 11 & $50.0 \pm 8.4$ & 9 & $2.8 \pm 0.7$ & $44.5 \pm 7.6$ & & & \\
\hline NGC 5238 & $<1.9$ & - & - & 0 & $<1.7$ & - & & & \\
\hline DDO 180 & $<2.9$ & $>3$ & $18.9 \pm 5.3$ & 5 & $<2.6$ & $16.9 \pm 5.1$ & $<7.4$ & - & $<6.6$ \\
\hline NGC 5433 & $19.0 \pm 1.8$ & 8 & $92.0 \pm 17.8$ & 10 & $17.4 \pm 1.7$ & $84.4 \pm 16.4$ & & & \\
\hline \multirow[t]{2}{*}{ NGC 6570} & $3.5 \pm 0.6$ & 18 & $6.1 \pm 1.3$ & 2 & $2.9 \pm 0.5$ & $5.0 \pm 1.1$ & & & \\
\hline & \multicolumn{9}{|c|}{ Im / I0 / Irr } \\
\hline ARP 004 & & & & & & & $<23.4$ & - & $<20.9$ \\
\hline NGC 899 & $<3.0$ & - & - & 0 & $<2.7$ & - & $10.6 \pm 1.9$ & $<2$ & $10.4 \pm 1.9$ \\
\hline NGC 1140 & & & & & & & $9.2 \pm 3.1$ & $<6$ & $8.7 \pm 2.9$ \\
\hline NGC 1602 & & & & & & & $9.7 \pm 2.6$ & $<1$ & $9.6 \pm 2.6$ \\
\hline NGC 1569 & $5.2 \pm 1.7$ & 2 & $18.3 \pm 5.6$ & 3 & $5.1 \pm 1.7$ & $17.9 \pm 5.5$ & & & \\
\hline UGC 3234 & $<4.6$ & - & - & 0 & $<4.1$ & - & & & \\
\hline NGC 2415 & $14.3 \pm 2.2$ & 9 & $14.3 \pm 2.2$ & 1 & $13.0 \pm 2.0$ & $13.0 \pm 2.0$ & & & \\
\hline NGC 2915 & & & & & & & $<13.1$ & - & $<11.7$ \\
\hline NGC 3077 & $3.1 \pm 1.0$ & 13 & $3.1 \pm 1.0$ & 1 & $2.7 \pm 0.9$ & $2.7 \pm 0.9$ & & & \\
\hline NGC 3396 & $<6.03$ & $>6$ & $4.8 \pm 1.6$ & 1 & $<5.4$ & $4.3 \pm 1.5$ & & & \\
\hline UGC 6345 & & & & & & & $<14.6$ & - & $<13.0$ \\
\hline NGC 3738 & $2.9 \pm 0.9$ & 2 & $7.7 \pm 2.3$ & 2 & $2.9 \pm 0.9$ & $7.6 \pm 2.3$ & & & \\
\hline NGC 4032 & & & & & & & $<14.3$ & - & $<12.7$ \\
\hline NGC 4190 & $<2.9$ & - & - & 0 & $<2.63$ & - & & & \\
\hline NGC 4194 & $12.2 \pm 2.2$ & 30 & $12.2 \pm 2.2$ & 1 & $8.5 \pm 1.7$ & $8.5 \pm 1.7$ & & & \\
\hline NGC 4485 & $<2.1$ & - & $7.3 \pm 1.9$ & 2 & $<1.9$ & $6.5 \pm 1.8$ & & & \\
\hline UGC 7690 & $<2.6$ & - & & 0 & $<2.3$ & - & & & \\
\hline IC 3476 & $<3.2$ & $>9$ & $5.6 \pm 1.2$ & 1 & $2.9 \pm 1.0$ & $5.0 \pm 1.2$ & & & \\
\hline NGC 4532 & $7.3 \pm 1.8$ & 4 & $7.3 \pm 1.8$ & 1 & $7.0 \pm 1.7$ & $7.0 \pm 1.7$ & $14.5 \pm 4.8$ & 4 & $13.9 \pm 4.7$ \\
\hline NGC 4630 & $<4.7$ & $>8$ & - & 0 & $<4.2$ & - & & & \\
\hline NGC 4810 & $<3.0$ & - & - & 0 & $<2.7$ & - & & & \\
\hline
\end{tabular}


Table 6. continued.

\begin{tabular}{|c|c|c|c|c|c|c|c|c|c|}
\hline \multirow[b]{2}{*}{ Name } & \multicolumn{6}{|c|}{ MRT } & \multicolumn{3}{|c|}{ SEST } \\
\hline & $\begin{array}{c}S_{1300 \mu \mathrm{m}} \\
{[\mathrm{mJy}]} \\
(2)\end{array}$ & $\begin{array}{c}S_{{ }^{12} \mathrm{CO}} / S_{1300 \mu \mathrm{m}} \\
{[\%]} \\
(3)\end{array}$ & $\begin{array}{c}\Sigma S_{1300 \mu \mathrm{m}} \\
{[\mathrm{mJy}]} \\
(4)\end{array}$ & $\begin{array}{c}\text { Number } \\
\text { of Chans. } \\
\text { (5) }\end{array}$ & $\begin{array}{c}S_{\text {dust }} \\
{[\mathrm{mJy}]} \\
(6)\end{array}$ & $\begin{array}{c}\sum S_{\text {dust }} \\
{[\mathrm{mJy}]} \\
(7)\end{array}$ & $\begin{array}{c}S_{1300 \mu \mathrm{m}} \\
{[\mathrm{mJy}]} \\
(8)\end{array}$ & $\begin{array}{c}S_{12 \mathrm{CO}} / S_{1300 \mu \mathrm{m}} \\
{[\%]} \\
(9)\end{array}$ & $\begin{array}{c}S_{\text {dust }} \\
{[\mathrm{mJy}]} \\
(10)\end{array}$ \\
\hline UGC 8303 & $<2.9$ & - & $3.7 \pm 0.9$ & 1 & $<2.6$ & $3.3 \pm 0.9$ & & & \\
\hline NGC 5408 & & & & & & & $<5.3$ & - & $<4.8$ \\
\hline NGC 5464 & & & & & & & $10.5 \pm 3.0$ & $<3$ & $10.2 \pm 2.9$ \\
\hline ARP 261 & $6.4 \pm 2.1$ & $<2$ & $16.1 \pm 4.4$ & 2 & $6.3 \pm 2.0$ & $15.8 \pm 4.3$ & $<14.8$ & - & $<13.2$ \\
\hline NGC 5798 & $3.0 \pm 0.8$ & 4 & $16.0 \pm 4.4$ & 5 & $2.9 \pm 0.8$ & $15.4 \pm 4.3$ & & & \\
\hline IC 4662 & & & & & & & $<8.6$ & - & $<7.7$ \\
\hline NGC 7292 & $<3.6$ & - & - & 0 & $<3.3$ & & & & \\
\hline & \multicolumn{9}{|c|}{ complementary galaxies } \\
\hline NGC 1012 & $6.7 \pm 2.1$ & 8 & $6.7 \pm 2.1$ & 1 & $6.2 \pm 2.0$ & $6.2 \pm 2.0$ & & & \\
\hline UGCA 116 & $13.3 \pm 3.1$ & 1 & $13.3 \pm 3.1$ & 1 & $13.3 \pm 3.1$ & $13.3 \pm 3.1$ & & & \\
\hline NGC 2976 & $<2.0$ & $>8$ & $22.7 \pm 5.4$ & 7 & $<1.8$ & $20.3 \pm 5.4$ & & & \\
\hline UGCA 247 & & & & & & & $<9.2$ & $>3$ & $<8.2$ \\
\hline NGC 7107 & & & & & & & $<6.0$ & - & $<5.4$ \\
\hline
\end{tabular}

\section{References}

Braine, J., Krügel, E., Sievers, A., \& Wielebinski, R. 1995, A\&A, 295, L55

Buisson, G., Desbats, L., Duvert, G., et al. 1997, Continuum and Line Analysis Single-dish Software, Observatoire de Grenoble and IRAM

Chini, R., Krügel, E., \& Lemke, R. 1996, A\&AS, 118, 47

Clemens, M. S., Alexander, P., \& Green, D. A. 1999, MNRAS, 307, 481

de Vaucouleurs, G., de Vaucouleurs, A., \& Corwin, H. G. 1976, Second Reference Catalogue of Bright Galaxies (Austin: University of Texas Press)

de Vaucouleurs, G., de Vaucouleurs, A., Corwin, et al. 1991, Third Reference Catalogue of Bright Galaxies (New York: Springer)

Elfhag, T., Booth, R. S., Höglund, B., Johansson, L. E. B., \& Sandqvist, A. 1995, A\&AS, 115, 439

Federspiel, M., Tammann, G. A., \& Sandage, A. 1998, ApJ, 495, 115

Heydari-Malayeri, M., Melnick, J., \& Martin, J.-M. 1990, A\&A, 234, 99

Ho, L. C., Fillipenko, A. V., \& Sargent, W. L. W. 1997, ApJS, 112, 315

Kraan-Korteweg, R. C. 1986, A\&AS, 66, 255
Kreysa, E. 1990, in Proc. 29th Liège International Astrophysical Colloq., From Ground-Based to Space-Borne Sub-mm Astronomy (ESA SP-314), ed. J.-P. Swings, \& D. Fraipont (Noordwijk: ESA Publications Division), 265

Krügel, E., Chini, R., Kreysa, E., \& Sherwood, W. A. 1988a, A\&A, 190, 47

Krügel, E., Chini, R., Kreysa, E., \& Sherwood, W. A. 1988b, A\&A, 193, L16

Krügel, E., Steppe, H., \& Chini, R. 1990, A\&A, 229, 17

Makarova, L. N., \& Karachentsev, I. D. 1998, A\&AS, 133, 181

Melisse, J. P. M., \& Israel, F. P. 1993a, A\&AS, 103, 391

Melisse, J. P. M., \& Israel, F. P. 1993b, A\&A, 285, 51

Meurer, G. R., Mackie, G., \& Carignan, C. 1994, AJ, 107, 2021

Schneider, S. E., Thuan, T. X., Mangum, J. G., \& Miller, J. 1992, ApJS, 81, 5

Sharina, M. E., Karachentsev, I. D., \& Tikhonov, N. A. 1999, AstL, 25,322

Tikhonov, N. A., \& Karachentsev, I. D. 1998, A\&AS, 128, 325

Thum, C., Kreysa, E., \& John, D. 1992, IRAM Working Report No. 212, IRAM, Grenoble

Tully, B. R. 1988, Nearby Galaxies Catalog (Cambridge: Cambridge University Press)

Ulich, B. L., \& Haas, R. W. 1976, ApJS, 30, 247 
M. Albrecht et al.: Dust and molecular gas in Magellanic type galaxies and irregulars. I., Online Material p 1

\section{Online Material}


M. Albrecht et al.: Dust and molecular gas in Magellanic type galaxies and irregulars. I., Online Material p 2
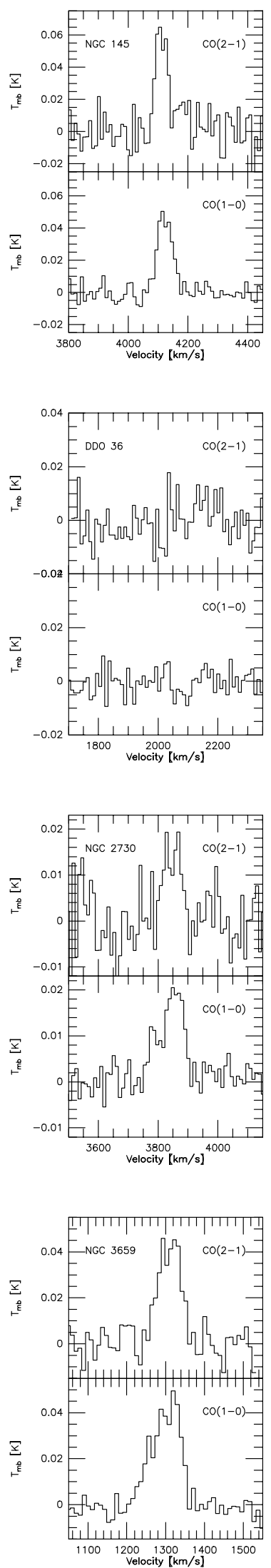
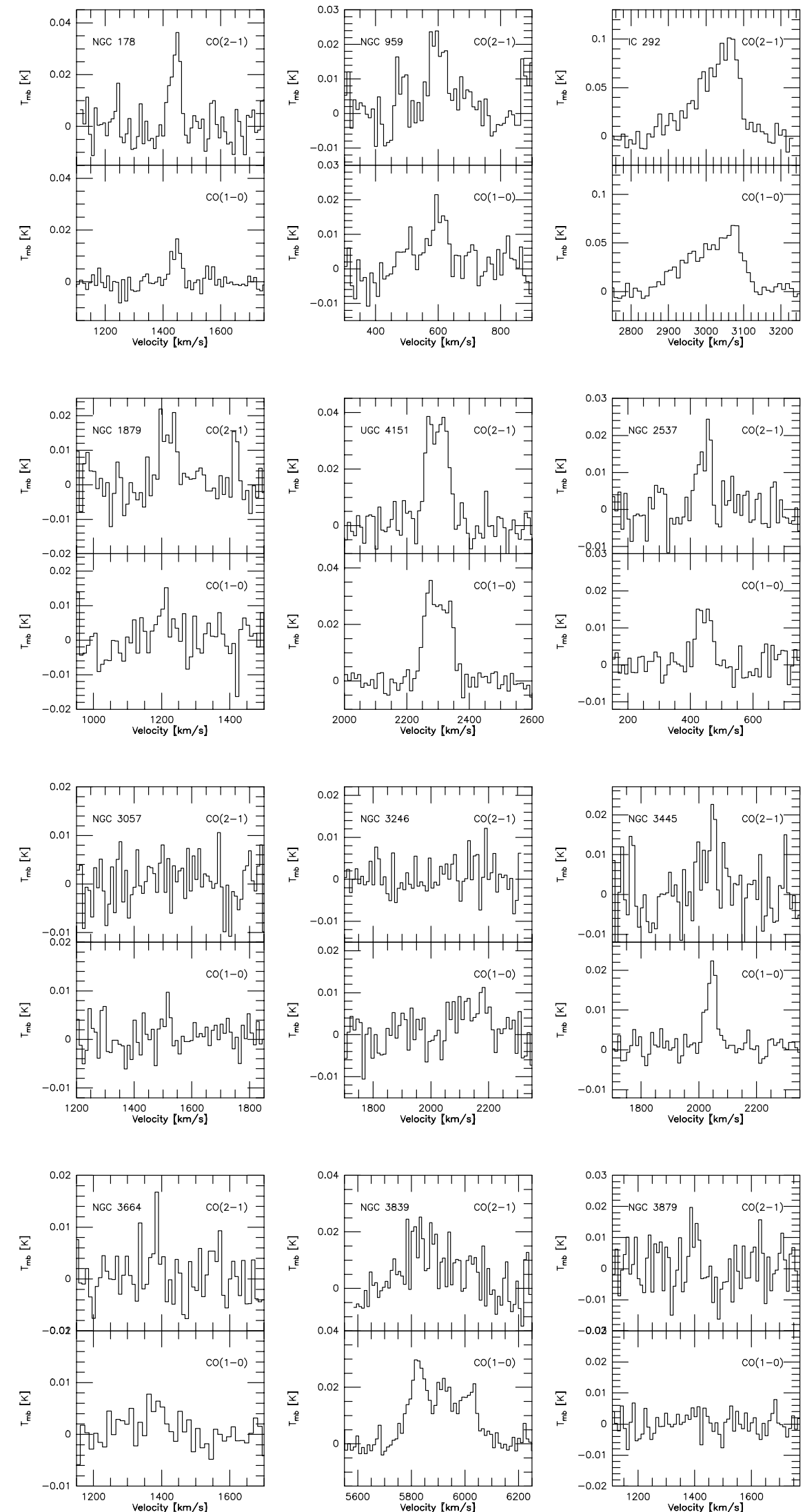

Fig. 3. continued. 
M. Albrecht et al.: Dust and molecular gas in Magellanic type galaxies and irregulars. I., Online Material p 3
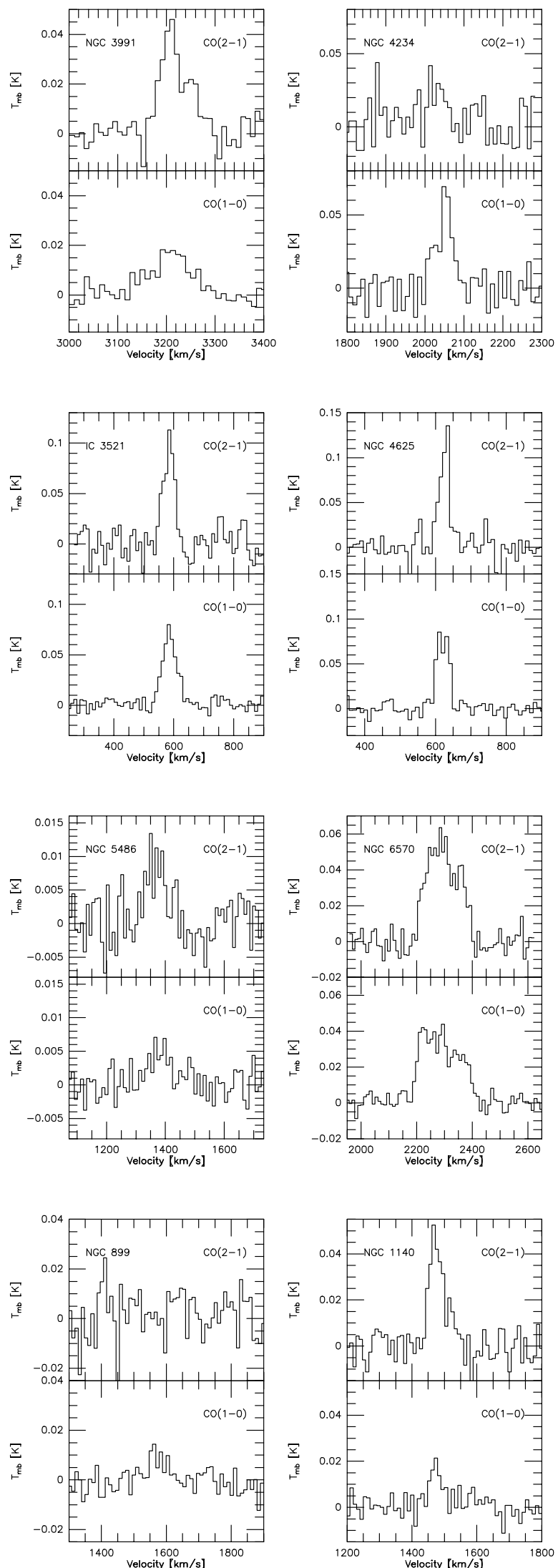
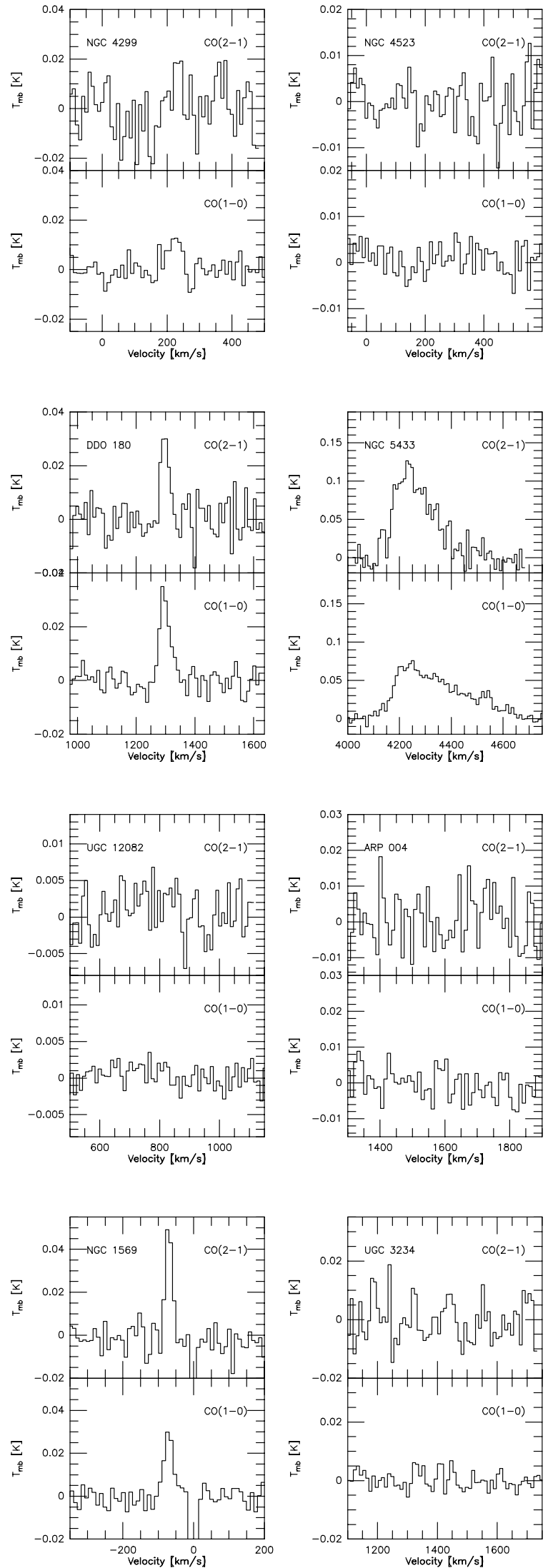

Fig. 3. continued. 
M. Albrecht et al.: Dust and molecular gas in Magellanic type galaxies and irregulars. I., Online Material p 4
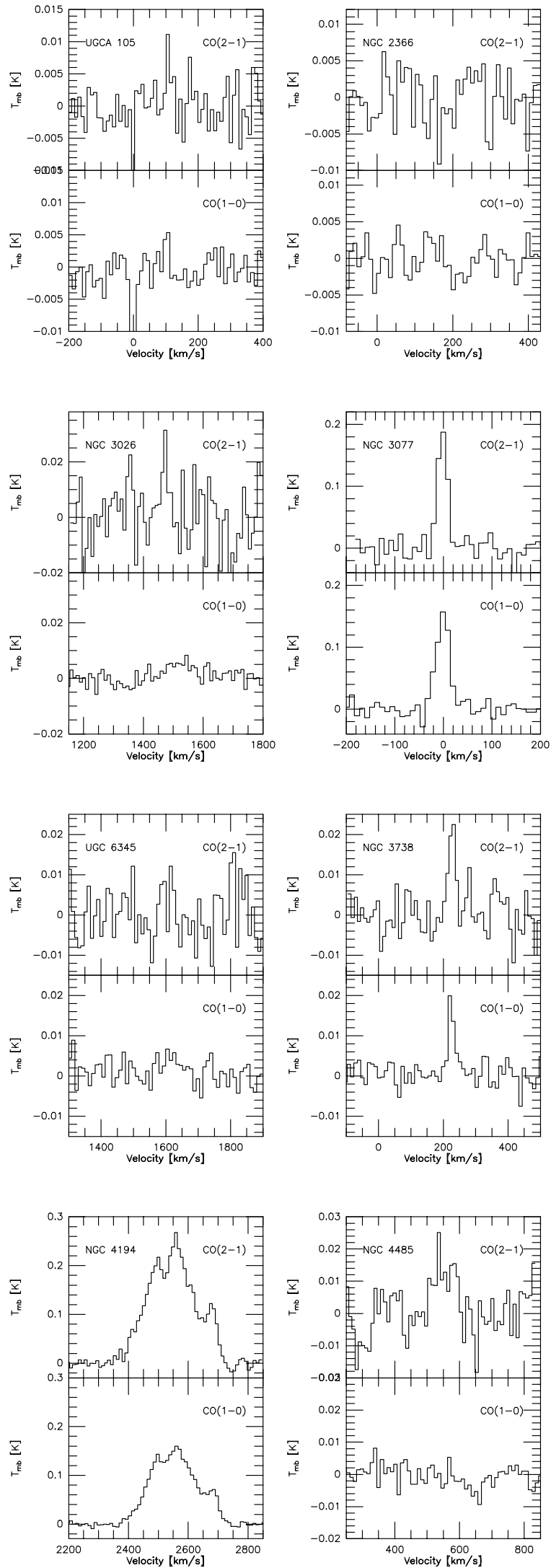
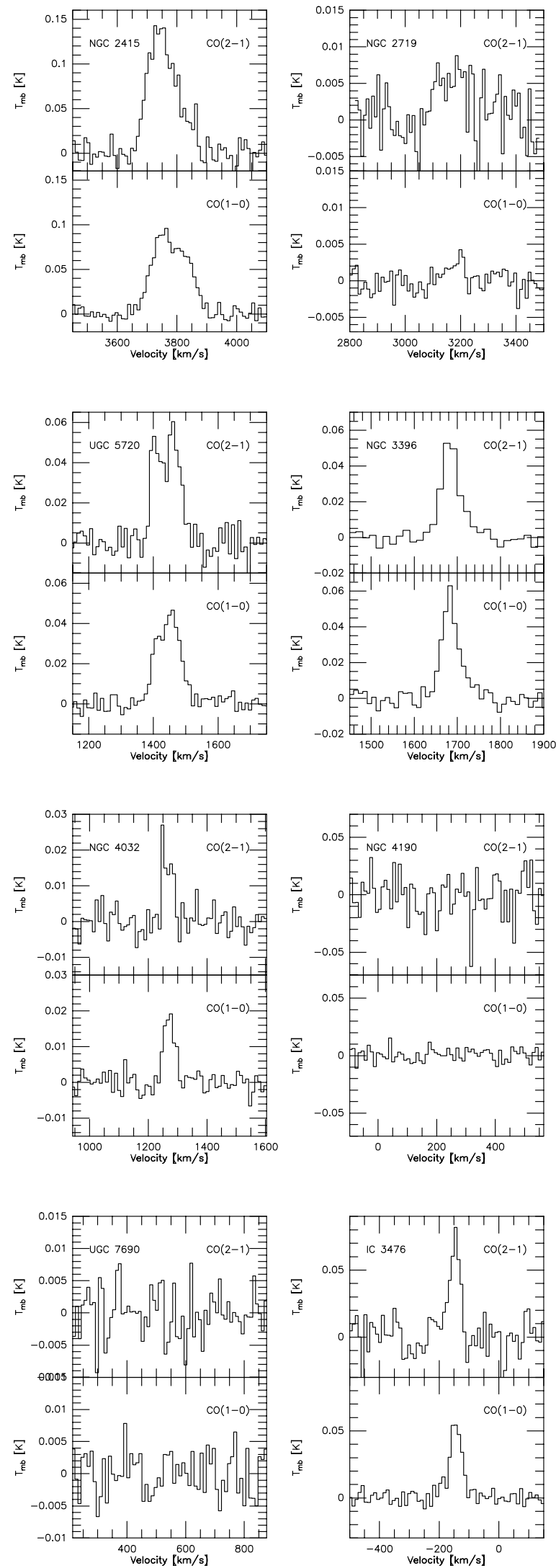

Fig. 3. continued. 
M. Albrecht et al.: Dust and molecular gas in Magellanic type galaxies and irregulars. I., Online Material p 5
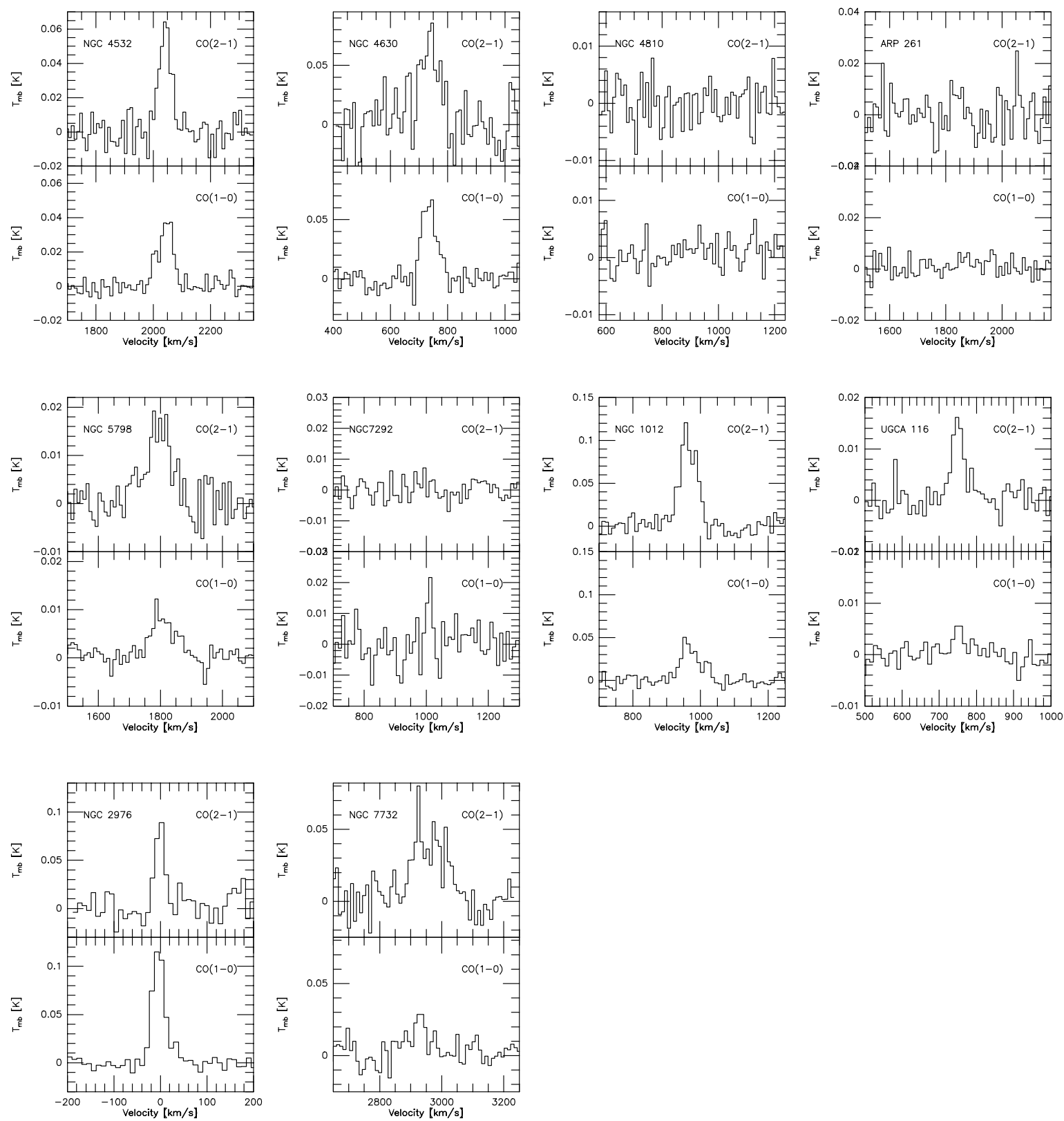

Fig. 3. continued. 
M. Albrecht et al.: Dust and molecular gas in Magellanic type galaxies and irregulars. I., Online Material p 6
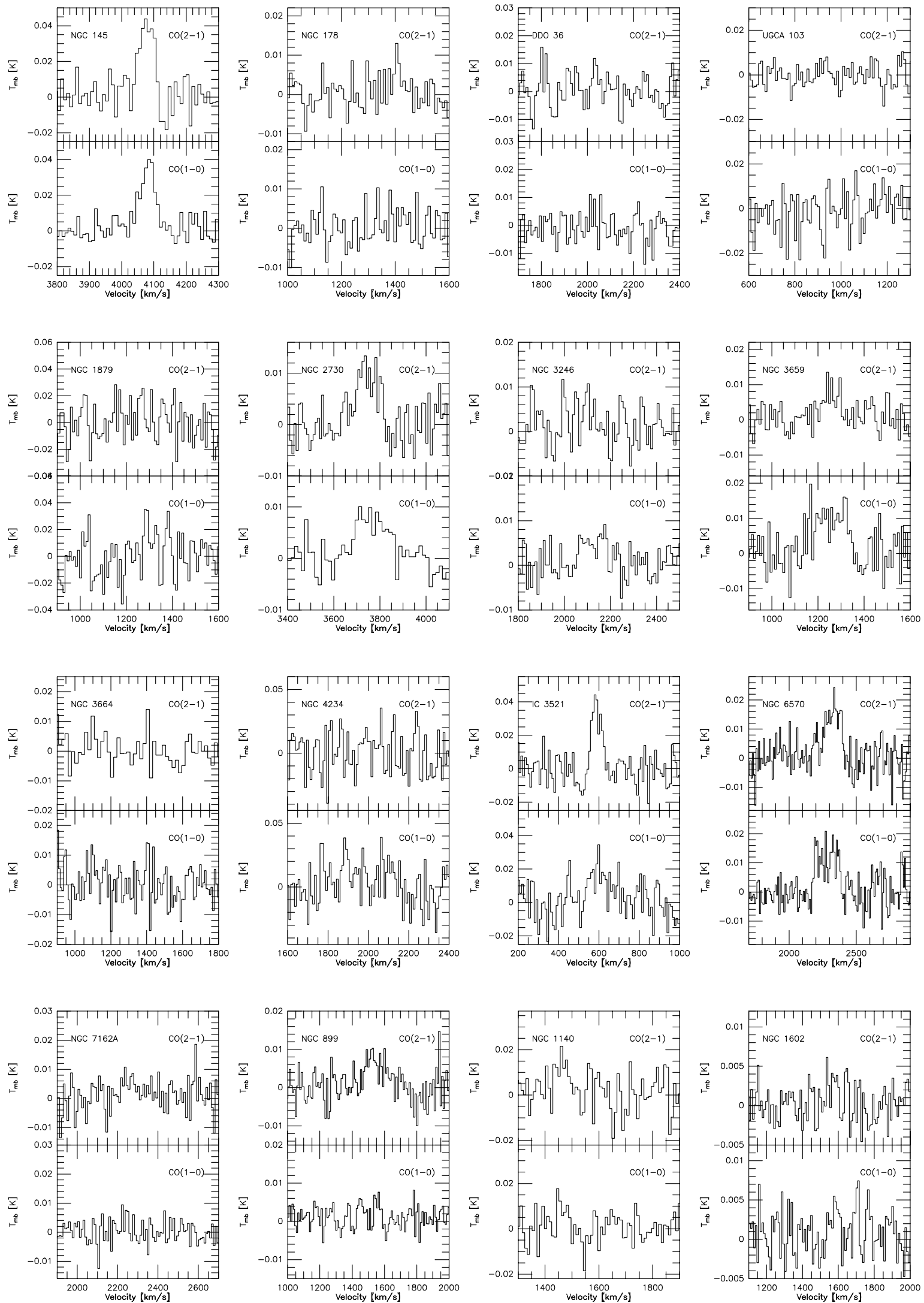

Fig. 4. continued. 
M. Albrecht et al.: Dust and molecular gas in Magellanic type galaxies and irregulars. I., Online Material p 7
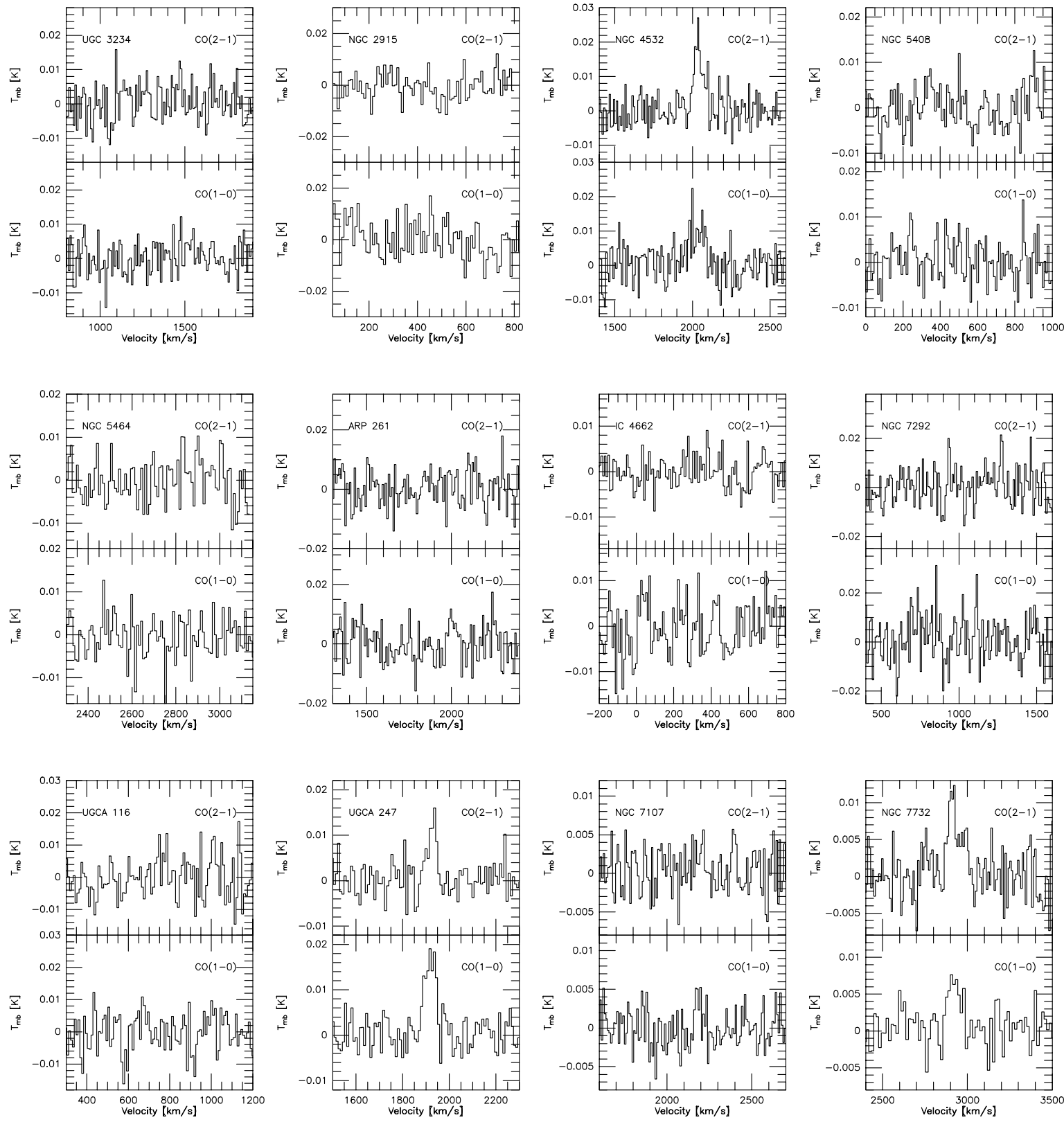

Fig. 4. continued. 